\title{
Disruptions of Circadian Rhythms and Thrombolytic Therapy During Ischemic Stroke Intervention
}

\author{
Jennifer A. Liu' ${ }^{1 *}$, James C. Walton ${ }^{1}$, A. Courtney DeVries ${ }^{1,2,3}$ and Randy J. Nelson ${ }^{1}$ \\ ${ }^{1}$ Department of Neuroscience, Rockefeller Neuroscience Institute, West Virginia University, Morgantown, WV, United States, \\ ${ }^{2}$ Department of Medicine, Division of Oncology/Hematology, West Virginia University, Morgantown, WV, United States, \\ ${ }^{3}$ West Virginia University Cancer Institute, West Virginia University, Morgantown, WV, United States
}

OPEN ACCESS

Edited by:

Radhika Basheer,

Harvard Medical School,

United States

Reviewed by:

Koji L. Ode,

The University of Tokyo, Japan

Masashi Tabuchi,

Case Western Reserve University,

United States

*Correspondence:

Jennifer A. Liu

jal0075@mix.wvu.edu

Specialty section:

This article was submitted to Sleep and Circadian Rhythms, a section of the journal

Frontiers in Neuroscience

Received: 03 March 2021

Accepted: 11 May 2021

Published: 10 June 2021

Citation:

Liu JA, Walton JC, DeVries AC and Nelson RJ (2021) Disruptions of Circadian Rhythms and Thrombolytic Therapy During

Ischemic Stroke Intervention.

Front. Neurosci. 15:675732. doi: 10.3389/fnins.2021.675732
Several endogenous and exogenous factors interact to influence stroke occurrence, in turn contributing to discernable daily distribution patterns in the frequency and severity of cerebrovascular events. Specifically, strokes that occur during the morning tend to be more severe and are associated with elevated diastolic blood pressure, increased hospital stay, and worse outcomes, including mortality, compared to strokes that occur later in the day. Furthermore, disrupted circadian rhythms are linked to higher risk for stroke and play a role in stroke outcome. In this review, we discuss the interrelation among core clock genes and several factors contributing to ischemic outcomes, sources of disrupted circadian rhythms, the implications of disrupted circadian rhythms in foundational stroke scientific literature, followed by a review of clinical implications. In addition to highlighting the distinct daily pattern of onset, several aspects of physiology including immune response, endothelial/vascular and blood brain barrier function, and fibrinolysis are under circadian clock regulation; disrupted core clock gene expression patterns can adversely affect these physiological processes, leading to a prothrombotic state. Lastly, we discuss how the timing of ischemic onset increases morning resistance to thrombolytic therapy and the risk of hemorrhagic transformation.

Keywords: circadian rhythm, stroke, prothrombotic state, TPA, hemorrhagic transformation, light at night (LAN), time of day, thrombolysis (tPA)

\section{INTRODUCTION}

Stroke, caused by a sudden interruption to the blood supply of the brain, has a wide range of detrimental consequences that have contributed to its recognition as the leading cause of disability and second most common cause of death worldwide. It has serious social and economic consequences for both the individual and society. Ischemic strokes account for the majority of all strokes (87\%), with intracerebral hemorrhages and subarachnoid hemorrhages being far less common (10\% and 3\%, respectively (Mozaffarian et al., 2016). Current FDA approved pharmaceutical treatment for acute ischemia is limited to thrombolytic intervention, which functions to restore blood flow, yet patients often still suffer long term motor, behavioral, and cognitive deficits due to a lack of interventions focused on promoting neuronal post-stroke recovery (Stubblefield and Lechleiter, 2019). Tissue plasminogen activator (tPA), is a naturally produced protein in endothelial cells that functions as a serine protease, catalyzing the conversion of 
plasminogen to plasmin, which acts as a key player in fibrinolysis. This protease has been used as a rapid and effective treatment during ischemic strokes by initiating reperfusion of the affected brain region, however, the therapeutic efficacy is limited to a 3-4.5-h time window from stroke onset (Cheng and Kim, 2015). Due to this limited intervention time, only about 3$5 \%$ of patients are eligible to receive tPA treatment (Fonarow et al., 2011) and $2-8 \%$ of that eligible population experience intracerebral hemorrhage as a consequence of receiving tPA (Miller et al., 2011).

Several aspects of physiology and behavior that are involved and contribute to ischemic injury are governed by the circadian system. Endogenous biological rhythms, modulated through external cues such as light, are important for adapting to predictable changes in the environment and maintaining internal physiology, which suggests the importance of time of day on health (Lowrey and Takahashi, 2000; Golombek and Rosenstein, 2010; Patke et al., 2020). Disruptions to these biological rhythms can dysregulate physiological function, including the cardiovascular system, metabolic and endocrine function and aspects of immune function (Davidson et al., 2010; Chen and Yang, 2015; Bedrosian et al., 2016; Serin and Acar Tek, 2019). In the context of ischemic stroke, several risk factors, including those described above, contribute to the severity of damage, patient recovery, and response to thrombolytic treatment (Seet et al., 2014; Arboix, 2015). Variability of patient response to ischemic stroke and its treatments, as well as considerations for the lack of consistency, suggests a need to consider circadian rhythms in order to optimize therapeutic strategies. This review will discuss the circadian regulation of several exogenous factors that influence risk for stroke and highlight time of day alterations in the efficacy of tPA administration and risk for hemorrhagic transformation.

\section{CIRCADIAN RHYTHMS, THE MAMMALIAN CLOCK}

Circadian rhythms are endogenous daily fluctuations in physiology and behavior driven through biological oscillators or clocks, and have been documented in most organisms, from bacteria to vertebrates (Bhadra et al., 2017). Physiological systems are optimized to promote biological adaptations and survival by adapting to the 24-h solar day (Daan and Aschoff, 1982). Circadian rhythms are driven and regulated through a transcriptional-translational feedback loop of core clock genes lasting approximately $24 \mathrm{~h}$ and are synchronized through exposure to the external light-dark cycle as a result of Earth's daily rotation. These external factors that can influence and synchronize the circadian rhythms to the environment are known as zeitgebers (German word for "time-giver"). Zeitgeber time $(\mathrm{ZT})$ is often used in circadian research to standardize time of day, and refers to the unit time based on the duration of time from initiation of the zeitgeber; for example, the onset of lights would be designated ZT 0 , whereas the onset of darkness $12 \mathrm{~h}$ later would be designated ZT 12. Thus, diurnal animals would be most active between ZT 0 and ZT12, whereas nocturnal organisms would be most active between ZT 12 and ZT 24 (Aschoff, 1981). Another fundamental component of circadian rhythms is the ability to persist in the absence of any external or environmental cues. Other external cues, including feeding, physical activity, and social cues, have the capacity to entrain circadian rhythms as well, but generally less effectively as light (Aschoff et al., 1971; Stephan, 2002; Lewis et al., 2018).

\section{Mechanism of the Molecular Circadian Clock}

The mechanism underlying cellular circadian clocks arises from an a transcriptional-translational autoregulatory feedback loop from a distinct set of genes including the Circadian Locomotor Output Cycles Kaput (Clock), Brain and Muscle ARNT-like Protein 1 (Bmal1), Period (Per), and Cytochrome (Cry). Clock and Bmal1 encode for proteins containing bHlhPAS domains, which form the positive arm of the feedback circuit by heterodimerizing to initiate transcription through binding to E-boxes ( $5^{\prime}$-CACGTG-3') and (5'-CACGTT-3') in the promoter of target genes. In turn, Per and Cry dimerize, acting as the negative limb of the feedback loop to inhibit Clock:Bmal1 transcriptional activity for the cycle to repeat, and degradation of Per and Cry proteins are responsible for terminating repression and restarting transcription. A second transcriptional feedback loop is initiated by the Clock:Bmal1 dimer which involves E-box mediated transcription of orphan nuclear-receptor genes $\operatorname{Rev}$-Erb $\alpha / \beta$ and $R O R \alpha / \beta$ (Preitner et al., 2002; Sato et al., 2004; Guillaumond et al., 2005). Rev-Erb has been implicated in normal period regulation (Cho et al., 2012), which competes with ROR proteins for Retinoic acid-related Orphan receptor Response Element (RORE) binding sites which are located within the promoter of Bmall. ROR proteins are responsible for initiating Bmal1 transcription, whereas Rev-Erb inhibits it (Preitner et al., 2002).

\section{Molecular Mechanisms Entraining and Modifying Central and Cellular Circadian Clocks}

Photoentrainment of the central circadian clock occurs primarily via light signals to intrinsically photosensitive retinal ganglion cells (ipRGCs) that depolarize and project through a monosynaptic neuronal pathway known as the retinohypothalamic tract (RHT) to the suprachiasmatic nucleus (SCN). The SCN serves as the master circadian clock in mammals and coordinates internal circadian synchronization; it sits at the top of a hierarchy of clocks of various tissue and cell types that display independent circadian gene expression patterns that are entrained by neural and humoral signals from the SCN (Tosini and Menaker, 1996; Balsalobre et al., 1998; Yamazaki et al., 2000). These non-image forming ipRGCs also function to regulate pineal melatonin secretion, the sleep/wake cycle, and pupillary constriction (Fu et al., 2005; Gamlin et al., 2007; Do and Yau, 2010) (Figure 1A).

Within the SCN, Per paralogs function as the state variable such that variations in the levels of proteins account for the 


\section{A}

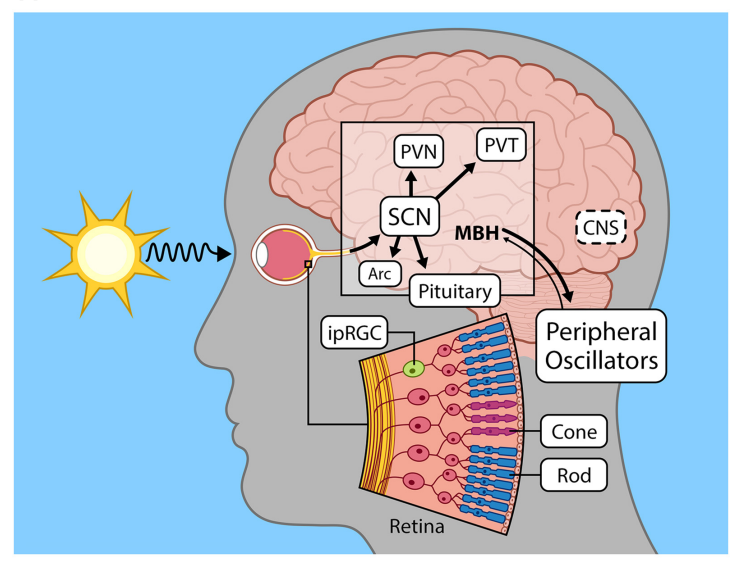

B

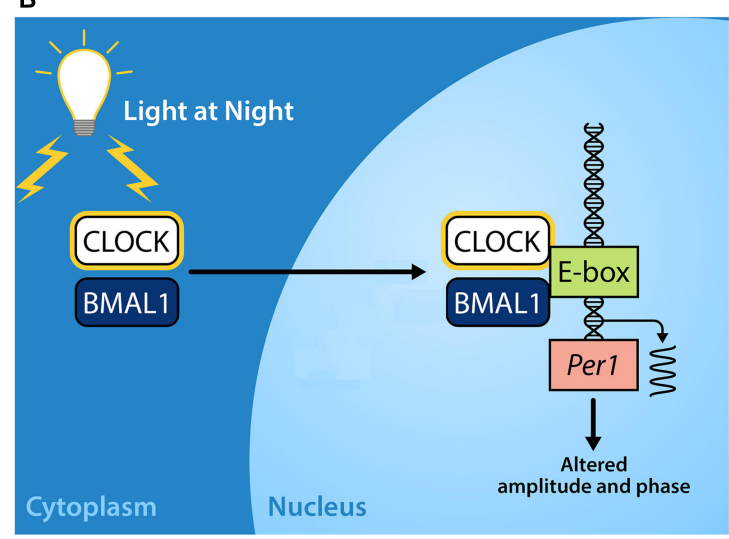

FIGURE 1 | (A) Light entrains the circadian clock. The light-dark cycle is the strongest zeitgeber, involved in synchronizing intrinsic circadian oscillations in the brain and periphery. Light energy in the form of photons enter the retina, depolarizing intrinsically photosensitive retinal ganglion cells (ipRGCs) which relay photic information via the retinohypothalamic tract to the so-called master circadian pacemaker, the suprachiasmatic nucleus (SCN) in the anterior hypothalamus. Direct and indirect projections of the SCN entrain other regions including local nuclei within the mediobasal hypothalamus $(\mathrm{MBH})$, the paraventricular nucleus $(\mathrm{PVN})$, paraventricular nuclei of the thalamus (PVT), arcuate nucleus (Arc). Endocrine signals from the pituitary gland and the pineal (melatonin secretion) that are initiated by the SCN provide time of day information to entrain peripheral oscillators. (B) Exposure to light at night disrupts the molecular circadian clock. The molecular clock in the cells of central and peripheral tissues is comprised of

transcriptional-translational feedback loops. The positive arm of the core circadian feedback loop involves the protein products of the genes circadian locomotor output cycles kaput (CLOCK) and brain and muscle arnt-like protein-1 (BMAL1), which heterodimerize in the cytoplasm, translocate to the nucleus, and bind to the E-box promotor regions of Period (Per) and Cryptochrome (Cry), driving their transcription. In the negative feedback arm of the core circadian feedback loop (not shown) Per/Cry protein products translocate to the nucleus to repress CLOCK/BMAL transcriptional activation, cycling with a period lasting approximately $24 \mathrm{~h}$ (please see Hurley et al., 2016; Rumanova et al., 2020) for further details on the molecular circadian clock). Exposure to light during the night disrupts Per1 expression resulting in altered circadian amplitude and phase.

phase of the clock (Kim et al., 2018). Acute exposure to light at any point during the dark period alters Perl expression in the core of the SCN (Shearman et al., 1997; Shigeyoshi et al., 1997) resulting in physiological and behavioral phase advances or delays. Exposure to light during the early dark phase results in increased Per2 expression in the shell of the SCN whereas light exposure late in the dark phase increases Per1 expression in the shell of the SCN, leading to a phase delay or phase advance in activity rhythms, respectively (Yan and Silver, 2004). This activation of Per paralogs occurs through CREB/MAPK signaling acting on cAMP-response elements (CRE) in Per promoters (Travnickova-Bendova et al., 2002).The functions of mammalian cellular clock proteins are additionally regulated through posttranslational modifications through various kinases, methylation, polyadenylation, histone modifications, and noncoding RNAs (Cardone et al., 2005; Mendoza-Viveros et al., 2017; Okamoto-Uchida et al., 2019). Phosphorylation was first discovered to be of major importance in vertebrate circadian clock regulation in the tau mutation in Syrian hamsters, where a lowered rate of CKI-dependent phosphorylation of Per2 occurred, resulting in shortened period of free running rhythms (Lowrey et al., 2000). Other post-translational regulators including Casein kinase II (CKII), PI3-kinase (PI3K), and c-Jun N-terminal kinases (JNKs) have also been implicated in modifying the cellular circadian clock, and may be critical for precise control of cellular circadian rhythms. The molecular details of precise regulation of the cellular circadian clock are outside the scope of this review; however, we note that stability, subcellular localization, transcriptional activity, and interactions among proteins and signaling pathways are also under circadian control (reviewed in Okamoto-Uchida et al., 2019).

\section{SOURCES OF CIRCADIAN DISRUPTION}

Daily rhythms of natural bright days and dark nights have shaped the evolution of internal biological clocks almost since the emergence of life, from physiological pathways to behavior. During the past century, widespread adoption of electric lighting and shifts in daily activity in the form of night shift work and social jet lag schedules has drastically affected circadian organization. Despite the seemingly innocuous nature of prolonged and inconsistent exposure to light in the evening, phase shifts from shift work, or social/leisure activities, several aspects of behavior and physiology have been affected (Navara and Nelson, 2007).

\section{Environmental Lighting}

The light-dark exposure patterns of humans have vastly changed over the past 100 years with the progression of civilization and industrialization, resulting in exposure to artificial light at night, or alternatively known as light pollution. Sources of illumination include street, architectural, and vehicle lighting, producing radiance from towns and cities via sky glow. Furthermore, light pollution introduces intensities and spectrums of light that differ significant from naturally occurring starlight and moonlight (Gaston et al., 2014). Approximately 5 lux of light exposure during the night is consistent with current light pollution levels in urban areas (Gaston et al., 2012) and sleeping 
environments (Obayashi et al., 2018). In comparison, the full moon is generally 0.05-0.2 lux of light at night (Kyba et al., 2017b). The light spectrum also varies depending on the light source used, ranging from high pressure sodium bulbs with broad bands of mainly yellow-orange wavelengths to high intensity discharge and light-emitting diodes (LEDs) producing narrow bandwidths with a strong peak of blue wavelengths in the spectrum, creating the appearance of whiter lighting (Falchi et al., 2011). This shift from incandescent bulbs to LEDs occurred during the early 21 st century based on reduced energy consumption and cost from the more energy efficient bulbs. IpRGCs are most sensitive to short wavelength (i.e., blue/violet light; $\sim 459 \mathrm{~nm}$ ) light (Wahl et al., 2019), and exposure to as little as $1.9 \mu \mathrm{W} \mathrm{cm} \mathrm{cm}^{-2}$ of light at night suppresses nightly melatonin production in humans (Thapan et al., 2001). Suppression of melatonin induced by lighting exposure during the night has been replicated in other mammalian species (Klein and Weller, 1972; Rollag et al., 1980; Benshoff et al., 1987).

This is a concern given that a recent study using light pollution propagation software and satellite data reports that $83 \%$ of the world's population reside under light-polluted skies $\left(>\mu \mathrm{cd} / \mathrm{m}^{2}\right)$, with that statistic jumping up to $99 \%$ in the United States and European populations (Falchi et al., 2016). Furthermore, light pollution levels have increased at a rate of $2.2 \%$ per year (Kyba et al., 2017a). Given the importance of light as a zeitgeber for humans and other species, nocturnal light exposure likely has serious consequences for health and wellbeing. Exposure to light during the dark phase can phase advance or delay the circadian clock (Schwartz et al., 2011), depending on the duration, timing, and intensity of the lighting source (Figure 1B). Low levels of artificial light at night (5 lux) disrupt circadian rhythmicity with a reduction in Per1 and Per2 expression in the SCN, concurrent with altered expression of Bmal1, Per1, Per2, and Cry 1 in the liver of mice (Fonken et al., 2013).

\section{Night Shift Work, Travel, and Social Jet Lag}

Coinciding with the increase in light pollution as a result of industrialization, current society has deviated from "9 to 5" workdays; the majority of the working population is engaged in "non-standard" or irregular hours, encompassing on-call work, weekend work, compressed weeks, telework, split-shifts, or more classically thought of as night shift work (Costa et al., 2004). Indeed, 15-30\% of adults are engaged in shift work according to American and European surveys (Boivin and Boudreau, 2014). Social jet lag, defined as the difference in lighting exposure and sleep time between work days and free days, is another form of circadian disruption that has become especially prevalent in adolescent and young adult populations (Valdez et al., 1996; Wittmann et al., 2006; Crowley et al., 2007). During social, travel jet lag, or shift work, desynchronization of central and peripheral oscillators occurs. Misalignments of circadian rhythms are responsible for "jet lag" syndrome characterized through fatigue, disturbed sleep rhythms, reduced alertness and ability to perform cognitive tasks, and headaches (Choy and Salbu, 2011).

\section{MOLECULAR CLOCK'S INFLUENCE ON CARDIOVASCULAR, CEREBROVASCULAR, AND IMMUNE PARAMETERS}

Circadian regulation of cardiovascular and cerebrovascular physiology is well documented (Kostenko and Petrova, 2018; Thosar et al., 2018), and includes heart rate and heart rate variability (Massin et al., 2000), sympathetic tone (Panza et al., 1991), blood pressure (Coca, 1994), and cerebral blood flow (Conroy et al., 2005; Hodkinson et al., 2014). Coordinated circadian patterns of these key physiological measures are crucial for meeting the increased physical demands of the active part of the day and the reduced demands of sleep. Aberrations in temporal rhythms can both directly and indirectly enhance cardiovascular and cerebrovascular disease (Bøggild and Knutsson, 1999), by enhancing sympathetic drive (Morris et al., 2012) increasing obesity (Shi et al., 2013), inducing insulin resistance and metabolic disorders (Marcheva et al., 2013), promoting premature aging (Brown et al., 2011), and inflammatory pathologies (Savvidis and Koutsilieris, 2012; Salavaty, 2015). These physiological perturbations can interact with cardiovascular phenotypes and prothrombotic states to play a significant role in stroke recurrence, functional outcome (Arboix, 2015), and outcome with pharmacological intervention with tissue plasminogen activator (tPA) (Seet et al., 2014). Cardiovascular tissue displays robust circadian oscillations in cells including vascular smooth muscle, fibroblasts, cardiomyocytes, and cardiac progenitor-like cells, all of which regulate physiological functions including endothelial function, blood pressure, and heart rate (Paschos and FitzGerald, 2010).

At the cellular level, the core clock genes, including Bmal1, Clock, Per, Cry, and Rev-Erb, play an important and vital role in maintaining physiological homeostasis. In addition to studies evaluating the role of time of day, genetic approaches can be used in basic science models to assess the role of specific genes within the molecular circadian clock. Notably, Bmal1, Clock, 1/2 Per double knock-out, and Cry1/2 double knock-out mice are completely arrhythmic (van der Horst et al., 1999; Bunger et al., 2000; Bae et al., 2001; DeBruyne et al., 2007), whereas single knockouts of Cry and Per have altered periods (van der Horst et al., 1999; Bae et al., 2001). Please see Cermakian et al. (2001) for a more extensive review of the circadian phenotypes of genetically altered models.

The next section will discuss how aberrations to circadian expression rhythms from environmental and genetic factors will alter cardiovascular, cerebrovascular, and immune parameters that increase stroke risk and contribute to the pathogenesis, damage, and outcome of cerebral ischemia (Brown et al., 2009; Ramsey et al., 2020).

\section{Coagulation, Hemostasis, and Fibrinolysis}

In response to vascular injury, platelets are activated upon coming in contact with subendothelial matrix proteins; 
platelet activation is responsible for clot formation in the procoagulant pathway, while several inhibitors function to inhibit clot propagation and avoid thrombus propagation (Palta et al., 2014). Several pro-inflammatory mediators including chemokines, adhesion molecules, vasoactive mediators, growth factors, and surface ligands are released upon platelet activation (Morrell et al., 2007). Indeed, this system relies on the intricacy of two systems in order to maintain fluidity and circulation of blood. In the context of cerebral ischemia, platelets play a crucial role in the pathogenesis of this condition; time of day alterations in factors involved in hemostasis and fibrinolysis contribute to a hyperfibrinolytic state, in turn increasing risk for stroke during morning time points.

In a study evaluating in vitro platelet aggregation in response to adenosine diphosphate (ADP) and adrenalin, platelet adhesiveness was measured using blood samples from healthy subjects (5 males and 5 females) over six timepoints (0800, 1200, 1600, 2000, 0000, and $0400 \mathrm{~h}$ ); prothrombin peaked at $1600 \mathrm{~h}$, suggesting a transient morning hypercoagulable state (Haus et al., 1990). Increased platelet activation along with fibrinogen, plasminogen-activator inhibitor 1 (PAI-1), plasmin-alpha-2-antiplasmin (PAP), and thrombin-antithrombin (TAT) complexes has been observed in healthy human volunteers (20-50 years old) during the morning $(0800 \mathrm{~h})$, with increasing concentrations of endogenous tPA, d-dimers, and PT prolongation in the afternoon (Budkowska et al., 2019). Clotting times were significantly reduced during the active period (night) in nocturnal rats, with increased prothrombin (II), factor VII, and factor $\mathrm{X}$ during the inactive period (day) (Soulban and Labrecque, 1989).

Coagulation and fibrinolysis has been further investigated in Clock mutant and Cry1/2 knockout (arrhythmic) mice; euglobulin clot lysis time was reduced in Clock mutants and significantly increased in Cry $1 / 2$-deficient mice without timeof-day differences (0900 and 2100 h). Further characterization showed reduced PAI-1 fluctuation in Clock mutant mice while Cry1/2-deficient mice held similar levels at both 0900 and $2100 \mathrm{~h}$ (Ohkura et al., 2006). Deficiencies in Bmall, showed hypercoagulable states, increased arterial and venous thrombogenicity, that lead to progressive dysfunction in endothelial cells and subsequent increased platelets and factor VII with age (Hemmeryckx et al., 2019). In common with these findings, vascular occlusion time was increased in this mutant mouse (Westgate et al., 2008). Bmal knockout (arrhythmic) mice display progressing prothrombotic state characterized by reduced prothrombin times, increased platelet count, a reduction in nitric oxide/thrombomodulin expression from endothelial cells (Hemmeryckx et al., 2011). Clock is also involved in the regulation of hemostasis. Mutations in Clock increased the total and active PAI1 levels along with reduced tPA in plasma (Westgate et al., 2008). Taken together, these results suggest that core clock genes are involved in regulating expression of key components in hemostasis and the fibrinolytic system, leading to an increased risk for the development of prothrombotic phenotypes and thus, an increased risk for cerebrovascular events.

\section{Vascular Function and the Blood-Brain Barrier}

The vascular system, specifically, the cerebrovasculature, has been implicated as an important role in brain development and regulation of homeostasis. Endothelial cells comprise the inner monolayer of blood vessels that forms a barrier between the artery wall and circulating blood is responsible for regulating vascular tone, regulation of hemostatic properties on the vascular surface, and determining blood-tissue/brain permeability (Paschos and FitzGerald, 2010). The bloodbrain barrier (BBB), is a tightly regulated system composed of transporters including permeability-glycoprotein (Pgp) and ATP-binding cassette sub-family B member 1 (ABCB1). Movement across the $\mathrm{BBB}$ occurs via transmembrane efflux pumps (Abbott et al., 2010) that transport molecules through endocytosis or through pores, carrier-mediated transport systems, or through direct permeation through the plasma membrane via lipophilic molecules (Banks and Kastin, 1992). These efflux pumps are regulated by ATP-binding cassette $(\mathrm{ABC})$ transporters or paracellular aqueous diffusion which are inhibited by tight junctions.

The BBB plays an integral role in the neuronal damage that evolves from disrupted blood flow. As a result of impaired blood supply, essential nutrients such as glucose and oxygen fail to adequately reach the ischemic core and surrounding region known as the penumbra. Endothelial ion transporters, including the $\mathrm{Na}-\mathrm{H}$ and $\mathrm{Na}-\mathrm{K}-\mathrm{Cl}$ cotransporter, become dysregulated upon neuronal injury, resulting in an imbalance of ionic gradients and cytotoxic edema that contribute to secondary neuronal damage (Pinheiro et al., 2016). Additionally, increased paracellular permeability (Keaney and Campbell, 2015), and increased immune cell trafficking, including infiltrating leukocytes, can exacerbate inflammatory responses, leading to increased neuronal damage and injury (Huang et al., 2006). Furthermore, disruptions to the $\mathrm{BBB}$ following thrombolytic intervention can be an early predictor for hemorrhagic transformation (Kastrup et al., 2008).

Evidence of an endogenous circadian rhythm in blood brain barrier permeability has been characterized in Drosophila where rhodamine B and daunorubicin concentrations were significantly increased in the brain during the rest phase (ZT 12) compared to their active phase through increased efflux activity via pgplike transporters during the day (Zhang et al., 2018). This oscillation was abolished in Per deficient flies (altered period) (Zhang et al., 2018). Further, several molecules, including tumor necrosis factor alpha (TNF $\alpha)$, leptin, $\beta$-amyloid, deltasleep inducing peptide (DSIP), and prostaglandin D2 (PGD2) display changes of rhythmic entry into murine CNS (Cuddapah et al., 2019). Other aspects of the blood brain barrier including integrity are also under circadian control. Bmal1 deficient mice display hyperpermeability and downregulation of plateletderived growth factor receptor $\beta$ (PDGFR $\beta$ ), suggesting a 
significant role for Bmall in pericyte regulation for blood-brain barrier maintenance (Nakazato et al., 2017).

Secondly, vascular function and tone also demonstrate robust core clock rhythms, best characterized through blood pressure peaks which are observed prior to the onset of the active cycle (light phase in diurnal species) followed by mid-morning peaks and decreases during the evening (inactive phase) (Millar-Craig et al., 1978). Additionally, a time-of-day dependent vasoreactivity exists (Durgan et al., 2017), further supporting the notion of circadian regulation of the cardiovascular system. Bmal1 knockout mice display lower blood pressure and abolished rhythmicity (Curtis et al., 2007), whereas Per1 has been implicated in aldosterone (Richards et al., 2013) and sodium regulation (Stow et al., 2012), both of which play a role in blood pressure maintenance. Selective deletion of Bmall in cardiomyocytes results in decreased heart rate from altered $\mathrm{Na}^{+}$and $\mathrm{K}^{+}$channels (Schroder et al., 2013), while deletion in smooth muscle cells advances systolic and diastolic blood pressure (Xie et al., 2015). Furthermore, Bmall deficient mice exhibit acute vascular dysfunction, vascular remodeling, and injury (Anea et al., 2009).

Nitric oxide (NO) and redox signaling involved in vascular contraction is another process that displays robust circadian oscillations involved in the vasoconstriction process. In the context of cerebral ischemia, NO synthases have both neuroprotective and damaging effects during brain hypoxia. Inducible NOS (NOS2) and neuronal NOS (NOS1) are involved in neurotoxicity, leading to excitotoxicity cascades, inflammation, apoptosis, and deterioration to the primary brain injury through the release of free radicals and production of nitrates, which directly damage mitochondrial enzymes and genetic material (Sims and Anderson, 2002; Chen et al., 2017). Endothelial NOS (NOS3) has a neuroprotective effect through regulation of cerebral blood flow, preventing neuronal injury, and inhibiting platelet and leukocyte adhesion (Liu et al., 2014). A study examining time of day variation in contractility response in mesenteric arteries isolated from Wistar rats reported increased NOS3 expression during the active period, which coincided with reduced vasoconstriction in response to phenylephrine and increased vasodilation response to acetylcholine during the active period (Rodrigo and Denniff, 2016). Further, NOS activity and cytosolic protein content was evaluated in Sprague-Dawley rats at 0300, 0900, 1500, and $2100 \mathrm{~h}$ in various regions of the brain including cerebellum, brainstem, hypothalamus, and hippocampus and reported that a significant upregulation during the dark (active) period (Ayers et al., 1996). Both endothelial nitric oxide synthase and NADPH oxidases (Nox), two factors involved in producing vasodilators (EDRF, EDHF, and PGI2) exhibit circadian variations in vasculature (Denniff et al., 2014). In addition to this time of day variation, disruption of circadian rhythms from exposure to dim light at night (dLAN; 1-2 lux) resulted in increased NOS3 protein expression in the arteries after 2 weeks of exposure in male Wistar rats (Molcan et al., 2019). Furthermore, NOS3 knockout mice display increased infarct sizes compared to wild type mice post middle cerebral artery occlusion (MCAO) (Huang et al., 1996). As mentioned above, NOS has significant neurotoxic impacts, and acts as a neuroprotective agent through mediation of vasodilation, plays a role in platelet aggregation inhibition, and contributes to endothelial leukocyte adhesion (Huang, 2007), and the studies above provide evidence and further support that disruptions to circadian rhythms support and increase neurotoxic effects and dampened neuroprotective aspects of NOS. In conclusion, several aspects of the vascular system are critically involved in acute injury and recovery from cerebral ischemia and are tightly regulated by core clock genes. Time of day alterations in function exist, suggesting a potential avenue for targeted therapeutic intervention. Thus, the BBB has reduced trafficking during the active phase compared to other time points during the day, along with an increased morning surge in blood pressure contributing to a heightened prothrombotic state, increasing risk for ischemia. Additionally, morning time points and studies evaluating circadian disruption have increased NOS, that can contribute toward neurotoxicity and secondary ischemic damage. Disruptions circadian rhythmicity in core clock gene expression patterns has vast implications contributing to increased stroke risk and impaired recovery.

\section{Immune System}

Components of the immune system are critical in pathophysiology of cerebral ischemia and are also regulated by the circadian clock. Acute cerebral hypoxia caused by thrombosis during ischemia triggers inflammatory cascades, and immune activation can cause secondary damage within the penumbra of the ischemic infarct (Kamel and Iadecola, 2012). Molecular clocks have been discovered in immune cells including macrophages/monocytes, T cells, NK cells, dendritic cells, and B cells (Ella et al., 2016), along with a circadian regulation in recruitment and infiltration of immune cells including neutrophils, monocytes/macrophages, and $\mathrm{T}$ cells, which infiltrate the injury site after the integrity of the BBB is compromised (Scheiermann et al., 2013). Rhythmic daily oscillations in both circulating innate and adaptive immune cells, and in cytokine and chemokines occur in the healthy brain (Labrecque and Cermakian, 2015), and circadian clock disruptions dysregulate immune response (Comas et al., 2017) and alters circulating proinflammatory cytokines, complement factors, and oxidative stress (Shivshankar et al., 2020).

In addition to the highly organized and regulated immune system, there are specific immune cell populations that exist in the CNS that are vital in maintaining normal brain homeostasis and function. Glial cells including microglia and astrocytes are non-neuronal populations in the central nervous system that function to maintain homeostasis, provide support, and protection, which are both involved in the innate and adaptive immune system (Herculano-Houzel, 2014; Zuchero and Barres, 2015). Inflammation is a key component and contributor in the pathophysiology of ischemia, existing in every stage of the ischemic cascade (Iadecola and Anrather, 2011). Upon neuronal and cell injury from ischemic infarction, glial populations function as the primary proponents in the early peri-infarct environment, however, have been implicated in both beneficial and a detrimental impact on the ischemic core (Xu et al., 2020). 
Microglia are a glial cell that plays an active role in immune surveillance in the central nervous system and are heavily involved in the initiation of the innate and adaptive immune response (van Rossum and Hanisch, 2004). This cell population accounts for up to $15 \%$ of all cells found within the brain (Lawson et al., 1992). This population plays a crucial role in triggering innate immune response by releasing pro and anti-inflammatory cytokines, chemokines, nitric oxide, prostaglandins, growth factors, and superoxide species that can modulate secondary injury and recovery (Loane and Byrnes, 2010). Microglia also recruit leukocytes, myeloid dendritic cells, monocytes/macrophages, and neutrophils to the site of ischemic damage during the earlier stages of stroke (Iadecola and Anrather, 2011; Jian et al., 2019). This activation process has a central role in initiating a neuroinflammatory response post stroke which can cause pathological progression of damage in the ischemic penumbra, however, aspects of the neuroinflammatory response are also critical for tissue repair (Yenari et al., 2010). Microglia are under circadian clock control, with robust hippocampal TNF $\alpha$, IL1 $\beta$, and IL6 expression, peaking during the light or inactive phase in male Sprague-Dawley rats, with increased cytokine expression in response to an immune stimulation with lipopolysaccharide (LPS) during the light/inactive phase (Fonken et al., 2015). Microglial activation, and interleukin expression specifically, is regulated by Bmal1 expression (Takano et al., 2009), along with a circadian variation in markers involved in oxidation, NADPH oxidase 2 (Nox2), and inflammatory TNF $\alpha, \operatorname{IL} 1 \beta$ and IL-6 in microglia increased during the light or inactive phase in nocturnal mice. Conversely, glutathione reductase (Gsr), heme oxygenase 1 (Hmoxl), glucose transporter member 5 (Glut5) and lipoprotein lipase (Lpl) were increased during the dark, or active period, suggesting that microglia have increased nutrient uptake during the active period. Wang et al. continued using Bmall knockout mice and reported altered clock gene expression (Cry2 and Per2) along with decreased Nrd1, Dbp, Il1 $\beta$, and Nox2 expression and increased Gsr and Lpl expression, indicating that Bmal1 regulates immune response and cellular metabolism in microglia (Wang et al., 2020). Other circadian clock proteins, such as Rev-erb $\alpha$ have also been implicated as a mediator of microglial activation and neuroinflammation, where the authors observed a time of day difference in microglial immunoreactivity in the hippocampus (Griffin et al., 2019). Further examination with Rev-erb $\alpha$ knockout mice, indicated increased basal nuclear factor $\kappa \mathrm{B}(\mathrm{NF} \kappa \mathrm{B})$ and enhanced hippocampal neuroinflammatory reactivity after inflammatory challenge (Griffin et al., 2019) providing further evidence of the role and importance of circadian clock regulation on immune function. These results also highlight the detrimental effects that result from altered circadian rhythms, and the downstream dysregulation of this highly conserved system.

Astrocytes are another specialized glial cell population integrated into both the vascular and neuronal system; and are critical for maintenance and survival of neurons during normal brain function (Stubblefield and Lechleiter, 2019). In the context of cerebral ischemia, astrocytes are especially important in regulation and maintenance of glutamate during acute injury, which causes excitotoxicity and perturbates calcium influx resulting in cell death (Brancaccio et al., 2017). Processes under astrocyte control including glutamatergic signaling (Beaulé et al., 2009) are regulated through the molecular clock, and in addition, extracellular glutamate displays rhythmicity, peaking during the mid-late day (inactive period) in mice. Disruptions to core clock genes including Per2, Clock, and NPAS2 display significant reductions in glutamate uptake, mRNA expression of Glast, an astrocyte-specific glutamate transporter, and protein expression (Sofroniew, 2015). Astrocytes are also involved in the recruitment of inflammatory cells to the site of injury, through the formation of a glial scar termed reactive astrogliosis which involves activation and proliferation of astrocytes to limit extending damage (Lananna et al., 2018). Astrocytic activation is regulated by Bmal1, shown through activation and increased inflammatory gene expression using an astrocyte specific Bmal1 knockout (Ali et al., 2020). Other studies using Bmal1 knockouts in astrocyte cultures have reported reduced actin-binding protein cortactin and impaired actin stress fiber formation (Ali et al., 2020).

Other immune cell populations that are involved in regulating the progression of ischemic injury are neutrophils, macrophages, and T-cells (Jian et al., 2019). As mentioned, the immune system is a tightly regulated system which is important to maintain health and survival. Appropriate inflammatory balance is especially important during ischemic injury, where there is major neuronal death and without proper neuroprotective measures, progressing injury can have detrimental effects on functional outcome and survival. Neutrophils are among the first immune cell populations to respond to ischemic injury; they are important for their phagocytotic properties to remove necrotic debris, but can result in neuroedema, disruption to the blood brain barrier, and collateral tissue damage (Jickling et al., 2015). Neutrophils have been well characterized to display robust oscillating rhythms in blood (Casanova-Acebes et al., 2013), variations in Bmal1 expression (Gibbs et al., 2014), and time-of-day regulated infiltration into bone marrow, lung, liver, and spleen tissue (Casanova-Acebes et al., 2018). Macrophages and monocytes are other immune cells in the mononuclear phagocyte system that have robust cell-autonomous rhythms (Scheiermann et al., 2013). Clock genes such as Rev-erb repress distal enhancers resulting in the repression of macrophages (Lam et al., 2013), whereas Bmal1 which controls rhythmic trafficking of inflammatory monocytes to sites of inflammation (Nguyen et al., 2013). In the context of stroke, macrophages and monocytes function similar to neutrophils and are especially important for their phagocytotic abilities during ischemia. T-cells are one of the major white blood cell types involved in the adaptive immune system and migrate to the site of ischemic injury after the initial inflammatory cascade within $24 \mathrm{~h}$ (Jian et al., 2019) which is dependent on adhesion molecule expression in the endothelium (Arumugam et al., 2005). This infiltration is important, due to the high mortality rate associated with infection during the acute phase of stroke recovery (Shi et al., 2018). Helper T cells (TH1) can play a neuroprotective role during recovery through anti-inflammatory 
cytokines (IL-4, IL-5, IL-10, IL-13), however, cytotoxic T cells can also contribute toward secondary injury from cytotoxic granules (Arumugam et al., 2005). Circadian variations in $\mathrm{T}$ cell proliferation in the lymph nodes exist, where $\mathrm{T}$ cell proliferation was significantly greater during the dark or active period in mice compared to the light, which was abolished in Clock mutant mice (Marie-Pierre Hardy et al., 2021). Based on the crucial role that timing plays in stroke intervention, we conclude that circulating immune factors and immune response is most active during the morning. Upon neuronal injury, heightened immune activation is observed during the morning increasing the risk for neurocytoxicity and secondary damage compared to the evening. In addition, disruptions to circadian rhythms and core clock gene function through exposure to light at night disrupts immune function and increases neuroinflammation (Walker et al., 2020), that has been corroborated in an ischemic murine model in which $24 \mathrm{~h}$ of exposure to dLAN post stroke increased pro-inflammatory response (TNF- $\alpha$, IL-6, and IL-1) in the ipsilateral cortex that can further amplify secondary damage of the infarct (Weil et al., 2020). Disruptions to circadian rhythms can lead to a prothrombotic state,in which patients during the morning time point are especially at risk for poor outcome, further highlighting the importance of time of day when considering therapeutic strategies.

\section{CLINICAL STUDIES, DISRUPTIONS TO CIRCADIAN RHYTHMS, AND STROKE}

During the late 20th century hospital analyses began to investigate the correlation between circadian variations in ischemic onset and outcome, highlighting the increased morning frequency of this cerebrovascular event. A meta-analysis of 31 publications ( 11,816 strokes) revealed a $49 \%$ increase of occurrence between 0600 and $1200 \mathrm{~h}$ in all types of strokes, and $79 \%$ increase over normalized risk compared to the other $18 \mathrm{~h}$ of the day (Elliott, 1998), with the lowest incidence of stroke reported between 0000 and $0600 \mathrm{~h}$ (Elliott, 1998). Additionally, mortality rates for strokes that occur during the morning were significantly higher, even when adjusted for sex, severity, and age (Turin et al., 2012). Analysis of stroke bank data revealed a significant increase in the number of strokes in awake patients from 1000 to $1200 \mathrm{~h}$, compared to any other 2-h interval throughout the day (Marler et al., 1989). Another study of 1223 patients reported increased frequency of acute ischemia between 0600 and $1200 \mathrm{~h}$; lacunar, thrombotic, and embolic strokes displayed increased frequency between 1801 and $0000 \mathrm{~h}$ (Lago et al., 1998). Ischemic stroke patients who experience "Wake-up Strokes," characterized by patients who were asleep for greater than $3 \mathrm{~h}$, with noted stroke symptoms upon waking between 0100 and $1100 \mathrm{~h}$ had increased diastolic blood pressure, a longer hospital stay. Further, this study indicated that patients were also at an increased risk for in-hospital mortality (Denny et al., 2014). In addition to an effect of time of day on risk, disrupted circadian rhythms also increase risk. Rotating shift work, which disrupts circadian rhythms, has also been associated with a $4 \%$ increased risk for ischemic stroke for every 5 years, with an increased risk of stroke in women with longer durations of shift work ( $\leq 15$ years) (Brown et al., 2009).

Together, the literature supports the notion that a time of day variation in stroke outcome exists, and that patients who experience stroke-like symptoms during the morning, or onset of the active period, have an increased risk for poor outcome. The data also suggest that it likewise could be possible to optimize therapeutic strategies based on the biological time that the onset of stroke occurs to improve survival rates. Time of day and circadian rhythms are both important variables in ischemia, and few clinical studies have considered these variables as biological factors. In this review we highlight the existence of circadian variations in ischemia and efficacy of thrombolytic intervention for clinicians, physicians, and pharmacists with the aim that time of day be recorded and reported as a biological variable in future clinical studies (Nelson and DeVries, 2017).

Other aspects of temporal organization influence and alter stroke recovery. For example, exposure to artificial lighting from hospital recovery units is a major issue (Korompeli et al., 2017). Indeed, clinicians need to monitor and treat patients $24 \mathrm{~h}$ a day, however, patients may be especially vulnerable to the influence of light at night due to their compromised state; frequent aspects of intensive hospital care units include frequent waking for vitals and procedures, and noise from equipment and staff (West et al., 2017). Few clinical studies to our knowledge have directly evaluated the role of dim nighttime lighting compared to dark nights on functional recovery and outcome in stroke, however, literature focused on normalizing naturalistic lighting during recovery have shown significant improvements (Wright et al., 2013). In the context of disrupted circadian rhythms, the use of naturalistic lighting optimizes light exposure similar to solar time, allowing for resynchronization of the internal biological clock to the natural light dark cycle (West et al., 2019). Using $24 \mathrm{~h}$ naturalistic lighting in rehabilitation units post-stroke found that patients experienced improved sleep with decreased disturbances, improved cognitive function, and endocrine function (Wang and Chen, 2020). Other studies using artificial sunlight exposure therapy during the day, with increasing morning blue-spectral illuminance peaking in the afternoon to imitate daylight for a minimum of 14 days of exposure in 4 weeks post stroke reported improved daily function through the Bartel Index and depressive test scores (Durgan et al., 2017). Thus, normalization through reentrainment of circadian rhythms to light dark cycles post cerebrovascular injury through the use of controlled lighting in a hospital setting is a non-invasive intervention that can potentiate improved recovery rates.

\section{TIME OF DAY ALTERATIONS ON ISCHEMIC STROKE OUTCOME (BASIC SCIENCE)}

As highlighted above, stroke incidence has a distinct time of day frequency, where studies identified a morning increase in 
frequency and mortality compared to any other time point in clinical studies (Marler et al., 1989). In addition to these time of day variations, basic science research has identified a circadian aspect in stroke severity, infarct volume, and functional outcome in rodents (Weil et al., 2009; Beker et al., 2018; Ramsey et al., 2020). In a controlled study, variation in ischemia/reperfusion tolerance across time of day has been previously explored, showing an increase in infarct volume and fibrosis at the onset of activity (ZT12) compared to the beginning of the inactive period (ZT0) in WT mice (Durgan et al., 2010). In addition, genetic ablation of the molecular clock in cardiomyocytes abolished this diurnal variation (Durgan et al., 2011). Global cerebral ischemia from cardiac arrest during the light (inactive) phase impaired survival and exacerbated outcome characterized by increased microglial activation, degenerating neurons, and proinflammatory cytokines in the hippocampus compared to dark (active) phase in $\mathrm{C} 3 \mathrm{H}$ mice (Weil et al., 2009). Studies into the molecular mechanisms underlying the time of day differences post ischemia revealed that ischemic/reperfusion injury at ZT 18 had reduced infarct volume, edema, neurological deficits, apoptotic death, and improved neuronal survival compared to other time points (ZT0, ZT6, ZT12, and ZT18), coinciding with a decrease in PRAS40 and increased expression of Bmal1, Per1, Clock, AKT, Erk-1/2, mTOR, S6, and BAD (Beker et al., 2018).

\section{Disruptions to Circadian Rhythms Influence on Ischemic Stroke (Basic Science)}

Disruptions to circadian rhythms prior to ischemic events leads to a prothrombotic state resulting in a heightened predisposition for enhanced stroke damage and poor outcome. Chronic circadian disruption through phase advances increased infarct volume in mice that received an MCAO (Ramsey et al., 2020). Another recent study reported that chronic disruption of circadian rhythms by a 12-h phase advance every 5 days for 7 weeks prior to MCAO increased infarct size in male and female Sprague Dawley rats. Further, male rats had increased mortality, while surviving females displayed a significant decrease in serum IGF-1 and nearly a doubling of infarct volume and sensorimotor deficits (Earnest et al., 2016).

In addition to disruption of circadian rhythms by repeated phase shifts (jet lag), foundational science research has examined the role of circadian disruption by light at night in stroke outcome. Studies evaluating the impact of ecologically relevant levels of dLAN (5 lux) have reported that stroke lesion size was significantly larger in dLAN mice compared to mice housed in dark nights after $24 \mathrm{~h}$ (Weil et al., 2020). Furthermore, this study reported that mice exposed to three days of dLAN post MCAO increased TNF- $\alpha$, IL- 6 , and IL- 1 in the ipsilateral hemisphere of the brain, and displayed increased anxiety-like behavior compared to control mice (Weil et al., 2020). Another study evaluating the effect of dLAN reports that as few as four days is sufficient to induce neuroinflammation in female mice (Walker et al., 2020) which can contribute toward neurotoxicity, increased neuronal damage within the penumbra, and delayed recovery post ischemia.

\section{Disruptions to Core Clock Genes (Basic Science)}

Disruptions to core circadian clock proteins, specifically Bmal1, has also resulted in increased reactive oxygen species, which is critical during mediation/exacerbation of damage during reperfusion in ischemia (Peek et al., 2017). Meanwhile, overexpression of Bmall and Clock may activate HIF-1 $\alpha$, involved in the regulation of innate neuroprotection (Lembach et al., 2018). Additionally, there is a difference between biological outcomes when comparing males and females post ischemic injury; the infarct core and both microglial activation and astrogliosis were significantly increased in females compared to males; furthermore, this sex difference persisted in female Bmal1 knockout mice that displayed increased core infarct size compared to wild type females (Wiebking et al., 2013). Per1 knockout mice increased neuronal cell death post ischemia compared to wild-type control mice. Importantly, ischemic injury during time points coincident with low Per1 expression were more susceptible to apoptosis compared to high Per1 expression (Jickling et al., 2014). Disruptions to core clock gene expression, which can occur from exposure to light at night or repeated phase shifts resulting from social jet lag can result in significant disruption in the tissue recovery process, which in the context stroke, could result in increased ischemic damage and could be detrimental to patient outcome.

\section{TPA AND CIRCADIAN RHYTHMS, AND FACTORS INVOLVED IN HEMORRHAGIC TRANSFORMATION}

Blood-brain barrier dysfunction is a well-characterized occurrence post ischemia; however, this component also contributes to hemorrhagic transformation and increased mortality post thrombolytic intervention (Lo et al., 2004). Hemorrhagic transformation occurs through a disruption in tight junction proteins, and investigations into this underlying mechanism found that dysregulated extracellular proteolysis in the vascular matrix after tPA contributes to hemorrhagic transformation (Chandler et al., 1990; Kurnik, 1995).

Endogenous active tPA is inversely proportional with PAI1 levels, peaking during the evening (Kastrup et al., 2008). A study evaluating blood-brain barrier opening shortly after cerebral ischemic onset correlated with an increased risk for intracerebral hemorrhage following exogenous tPA thrombolysis (Yang and Rosenberg, 2015). Furthermore, tPA intervention increased brain matrix metalloproteinase (MMP-9) (Yang et al., 2016), as well as phosphorylation of connexin43, a gap junction protein contributing to blood brain barrier permeability and hemorrhagic transformation (Tang and Han, 2013).

PAI-1, a serine protease inhibitor and another factor involved in the pathogenesis of stroke is produced primarily by the endothelium which directly acts as an active inhibitor 
of tPA and urokinase ( $\mathrm{uPA})$, a serine protease which is responsible for cleaving plasminogen to plasmin (Lakhan et al., 2013). Plasminogen regulates proteolytic and complement cascade (Barthel et al., 2012) which can contribute to thrombolysis or mediates degradation in conjunction with matrix metalloproteinases (Oishi, 2009). PAI-1 displays circadian rhythmicity, peaking during the morning (or the onset of the active period), in turn contributing to morning hypofibrinolysis (Schoenhard et al., 2003); elevated endogenous PAI-1 has been suggested to play a role in the morning peak of cardiovascular events (Scheer and Shea, 2014). Further in vitro work reported that the human PAI-1 promoter region in transfected endothelial cells is differentially activated by Bmal1 and Bmal2 (Somanath et al., 2011). In vivo work with Bmal1 knockout mice showed shorter cessation of tail bleeding, occlusion time post injury, increased plasma fibrinogen, and cessation of rhythmicity for PAI-1 (Sumii and Lo, 2002).

Matrix metalloproteinases (MMPs) involved in vascular matrix remodeling, specifically, MMP-2 and MMP-9 are upregulated after tPA administration in focal cerebral ischemia (Wang and Chen, 2020); MMP-9 concentrations were reduced in tPA knock-out mice (Rosenberg, 2002). Furthermore, neuroedema was reduced after intracerebral hemorrhage through MMP inhibitor administration (Wang et al., 2003). Lipoprotein receptor-related protein (LRP) also known as LDLR, expressed in neurons, astrocytes, and endothelial cells in the brain functions as a receptor for $\mathrm{TPA}$, mediating MMP upregulation, which in turn can contribute to hemorrhagic transformation from degradation

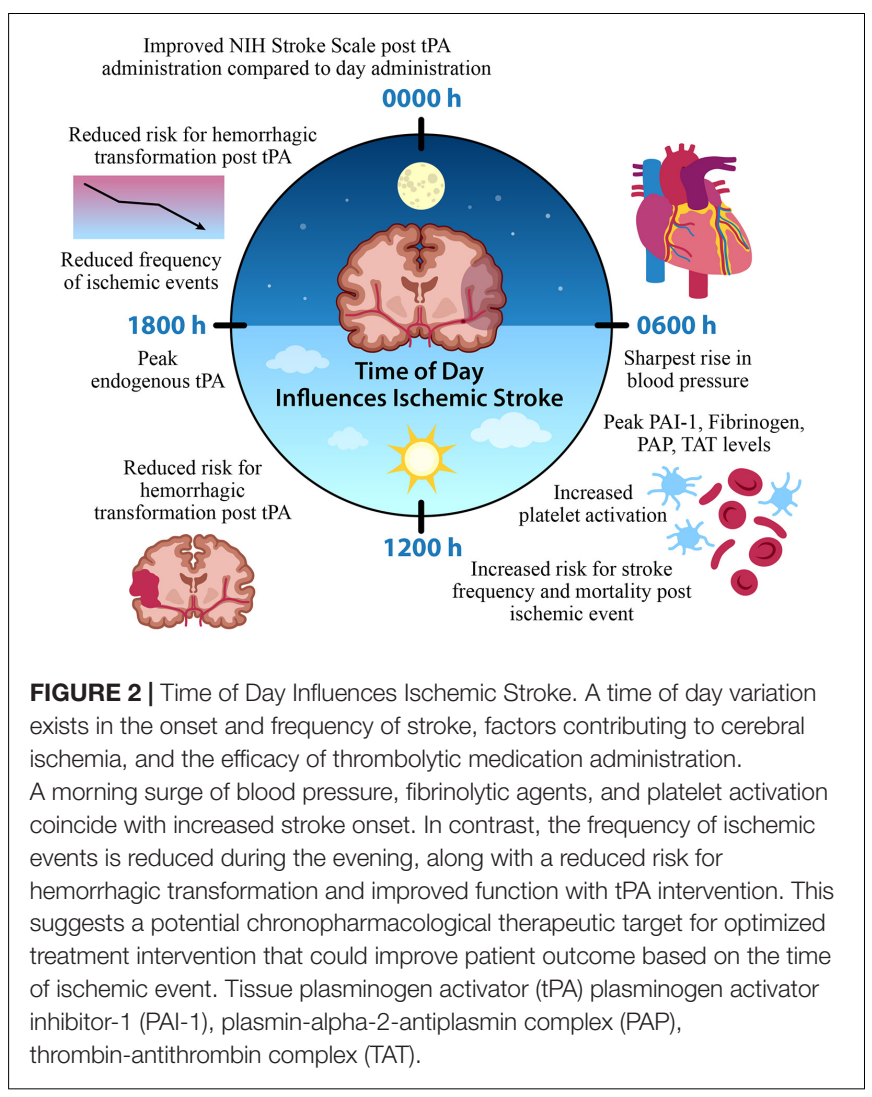

of the neurovascular matrix (Lee et al., 2012). LDLR/LRP expression is under circadian control through Clock/Bmall (Cappellari et al., 2014). Thus, LDLR/LRP may serve as a potential intervention point for time-of-day differences during ischemic onset and tPA intervention that could potentiate intracerebral hemorrhage.

\section{Clinical Studies and Time of Day Alterations in tPA Efficacy}

In the context of clinical studies, a small population study of 476 non-lacunar strokes treated with an IV infusion of tPA was interested in identifying possible circadian variation with thrombolytic intervention; patients who received IV thrombolysis at morning (0600-1200) and afternoon (1200$1800 \mathrm{~h}$ ) time points exhibited less improvement on the NIH Stroke Scale compared to other time points. Furthermore, hemorrhagic transformation was also lower in frequency for patients who started IV thrombolysis between 1200 and $1800 \mathrm{~h}$ compared to those who received treatment between 0000 and $0600 \mathrm{~h}$ (Marler et al., 1989). Together, evidence supports the role of time of day alterations in the efficacy of tPA and hemorrhagic transformation, as a potential negative consequence of tPA administration. Patients who have an ischemic stroke in the morning, or onset of their active period, are not only at a greater risk for poor outcome based on the hyperfibrinolytic morning state, but additionally, response to thrombolytic intervention is less efficacious during the morning time points. Alongside this, the time of day variation in stroke onset exists, where there's a significant increase in morning onset strokes (Marler et al., 1989). This further emphasizes the potential avenue for a significant improvement in a large proportion of stroke patient outcome where targeted thrombolytic intervention is modified based on time of onset (Figure 2).

\section{CONCLUSION}

Stroke requires a rapid diagnosis and quick intervention because of the limited time for thrombolytic intervention, highlighting the importance of timing for this disease. Biological timing and clock gene expression play important roles in the cerebrovascular and cardiovascular systems. Basic foundational research has clearly demonstrated time of day variation in function, and the detrimental consequences of disruptions to circadian rhythms and their impact on contributing to a prothrombotic state. In addition to the emphasized morning circadian distribution pattern of stroke frequency, clinical studies support improved functional outcome and recovery in patients who receive thrombolytic therapy during the evening; the morning hypofibrinolytic and hypercoagulable state, in combination with increased PAI-1 levels, may contribute to less effective tPA treatment in the morning. Furthermore, patients have significantly lower neurological improvement rates when tPA is administered in the morning compared to the evening, as well as increased hemorrhagic transformation post thrombolytic intervention during morning time points. Thus, optimizing thrombolytic treatment based on time of day onset and the 
reduction of exposure to exogenous environmental circadian disruptors, such as exposure to lighting at night, has the potential to reduce secondary damage during stroke recovery and improve functional outcome. The intricate relationship among circadian rhythms, disruptions, and the stroke outcome, emphasizes the importance of chronopharmacological research.

\section{AUTHOR CONTRIBUTIONS}

JL, JW, $\mathrm{AD}$, and RN designed, wrote, and edited the manuscript. JL designed the figures. All authors have read and agreed to the published version of the manuscript.

\section{REFERENCES}

Abbott, N. J., Patabendige, A. A. K., Dolman, D. E. M., Yusof, S. R., and Begley, D. J. (2010). Structure and function of the blood-brain barrier. Neurobiol. Dis. 37, 13-25. doi: 10.1016/j.nbd.2009.07.030

Ali, A. A. H., Schwarz-Herzke, B., Rollenhagen, A., Anstötz, M., Holub, M., Lübke, J., et al. (2020). Bmall-deficiency affects glial synaptic coverage of the hippocampal mossy fiber synapse and the actin cytoskeleton in astrocytes. Glia 68, 947-962. doi: 10.1002/glia.23754

Anea, C. B., Zhang, M., Stepp, D. W., Simkins, G. B., Reed, G., Fulton, D. J., et al. (2009). Vascular disease in mice with a dysfunctional circadian clock. Circulation 119, 1510-1517. doi: 10.1161/CIRCULATIONAHA.108.827477

Arboix, A. (2015). Cardiovascular risk factors for acute stroke: risk profiles in the different subtypes of ischemic stroke. World J. Clin. Cases 3:418. doi: 10.12998/ wjcc.v3.i5.418

Arumugam, T. V., Granger, D. N., and Mattson, M. P. (2005). Stroke and T-cells. Neuro Mol. Med. 7, 229-242.

Aschoff, J. (1981). "Freerunning and entrained circadian rhythms," in Biological Rhythms, ed. J. Aschoff (Cham: Springer), 81-93. doi: 10.1007/978-1-46156552-9_6

Aschoff, J., Fatranská, M., Giedke, H., Doerr, P., Stamm, D., and Wisser, H. (1971). Human circadian rhythms in continuous darkness: entrainment by social cues. Science 171, 213-215. doi: 10.1126/science.171.3967.213

Ayers, N. A., Kapás, L., and Krueger, J. M. (1996). Circadian variation of nitric oxide synthase activity and cytosolic protein levels in rat brain. Brain Res. 707, 127-130. doi: 10.1016/0006-8993(95)01362-8

Bae, K., Jin, X., Maywood, E. S., Hastings, M. H., Reppert, S. M., and Weaver, D. R. (2001). Differential functions of mPer $1, \mathrm{mPer} 2$, and mPer3 in the SCN circadian clock. Neuron 30, 525-536. doi: 10.1016/S0896-6273(01)00302-6

Balsalobre, A., Damiola, F., and Schibler, U. (1998). A serum shock induces circadian gene expression in mammalian tissue culture cells. Cell 93, 929-937. doi: 10.1016/S0092-8674(00)81199-X

Banks, W. A., and Kastin, A. J. (1992). Bidirectional passage of peptides across the blood-brain barrier. Prog. Brain Res. 91, 139-148. doi: 10.1016/S0079-6123(08) 62328-6

Barthel, D., Schindler, S., and Zipfel, P. F. (2012). Plasminogen is a complement inhibitor. J. Biol. Chem. 287, 18831-18842. doi: 10.1074/jbc.M111.323287

Beaulé, C., Swanstrom, A., Leone, M. J., and Herzog, E. D. (2009). Circadian modulation of gene expression, but not glutamate uptake, in mouse and rat cortical astrocytes. PLoS One 4:e007476. doi: 10.1371/journal.pone.000 7476

Bedrosian, T. A., Fonken, L. K., and Nelson, R. J. (2016). Endocrine effects of circadian disruption. Annu. Rev. Physiol. 78, 109-131. doi: 10.1146/annurevphysiol-021115-105102

Beker, M. C., Caglayan, B., Yalcin, E., Caglayan, A. B., Turkseven, S., Gurel, B., et al. (2018). Time-of-day dependent neuronal injury after ischemic stroke: implication of circadian clock transcriptional factor bmall and survival kinase AKT. Mol. Neurobiol. 55, 2565-2576. doi: 10.1007/s12035-017-0524-4

Benshoff, H. M., Brainard, G. C., Rollag, M. D., and Lynch, G. R. (1987). Suppression of pineal melatonin in Peromyscus leucopus by different

\section{FUNDING}

Preparation of this review was supported by the National Institute of Health grants R01NS092388 and a grant from the National Institute of General Medical Sciences of the National Institute of Health under Award Number 5U54GM104942-03. The content is solely the responsibility of the authors and does not necessarily represent the official views of the National Institute of Health.

\section{ACKNOWLEDGMENTS}

We thank Molly Thompson for preparing the figures.

monochromatic wavelengths of visible and near-ultraviolet light (UV-A). Brain Res. 420, 397-402. doi: 10.1016/0006-8993(87)91264-9

Bhadra, U., Thakkar, N., Das, P., and Pal Bhadra, M. (2017). Evolution of circadian rhythms: from bacteria to human. Sleep Med. 35, 49-61. doi: 10.1016/j.sleep. 2017.04.008

Bøggild, H., and Knutsson, A. (1999). Shift work, risk factors and cardiovascular disease. Scand. J. Work Environ. Health 25, 85-99. doi: 10.5271/sjweh.410

Boivin, D. B., and Boudreau, P. (2014). Impacts of shift work on sleep and circadian rhythms. Pathol. Biol. 62, 292-301. doi: 10.1016/j.patbio.2014.08.001

Brancaccio, M., Patton, A. P., Chesham, J. E., Maywood, E. S., and Hastings, M. H. (2017). Astrocytes control circadian timekeeping in the Suprachiasmatic nucleus via Glutamatergic signaling. Neuron 93, 1420-1435.e5. doi: 10.1016/j. neuron.2017.02.030

Brown, D. L., Feskanich, D., Sánchez, B. N., Rexrode, K. M., Schernhammer, E. S., and Lisabeth, L. D. (2009). Rotating night shift work and the risk of ischemic stroke. Am. J. Epidemiol. 169, 1370-1377. doi: 10.1093/aje/kwp056

Brown, S. A., Schmitt, K., and Eckert, A. (2011). Aging and circadian disruption: causes and effects. Aging 3, 813-817. doi: 10.18632/aging.100366

Budkowska, M., Lebiecka, A., Marcinowska, Z., Woźniak, J., Jastrzêbska, M., and Dołęgowska, B. (2019). The circadian rhythm of selected parameters of the hemostasis system in healthy people. Thromb. Res. 182, 79-88. doi: 10.1016/j. thromres.2019.08.015

Bunger, M. K., Wilsbacher, L. D., Moran, S. M., Clendenin, C., Radcliffe, L. A., Hogenesch, J. B., et al. (2000). Mop3 is an essential component of the master circadian pacemaker in mammals. Cell 103, 1009-1017. doi: 10.1016/S00928674(00)00205-1

Cappellari, M., Bovi, P., and Moretto, G. (2014). Circadian variation in the effect of intravenous thrombolysis after non-lacunar stroke. J. Thromb. Thrombolys. 38, 253-259. doi: 10.1007/s11239-013-1041-6

Cardone, L., Hirayama, J., Giordano, F., Tamaru, T., Palvimo, J. J., and SassoneCorsi, P. (2005). Cell biology: circadian clock control by SUMOylation of BMAL1. Science 309, 1390-1394. doi: 10.1126/science.1110689

Casanova-Acebes, M., Nicolás-Ávila, J. A., LiangYao Li, J., García-Silva, S., Balachander, A., Rubio-Ponce, A., et al. (2018). Neutrophils instruct homeostatic and pathological states in naive tissues. J. Exp. Med. 215, 27782795. doi: 10.1084/jem.20181468

Casanova-Acebes, M., Pitaval, C., Weiss, L. A., Nombela-Arrieta, C., Chèvre, R., A-González, N., et al. (2013). XRhythmic modulation of the hematopoietic niche through neutrophil clearance. Cell 153:1025. doi: 10.1016/j.cell.2013. 04.040

Cermakian, N., Monaco, L., Pando, M. P., Dierich, A., and Sassone-Corsi, P. (2001). Altered behavioral rhythms and clock gene expression in mice with a targeted mutation in the Period1 gene. EMBO J. 20, 3967-3974. doi: 10.1093/emboj/20. 15.3967

Chandler, W. L., Trimble, S. L., Loo, S. C., and Mornin, D. (1990). Effect of PAI-1 levels on the molar concentrations of active tissue plasminogen activator (t-PA) and t-PA/PAI-1 complex in plasma. Blood 76, 930-937. doi: 10.1182/blood.v76. 5.930 .930

Chen, L., and Yang, G. (2015). Recent advances in circadian rhythms in cardiovascular system. Front. Pharmacol. 6:71. doi: 10.3389/fphar.2015.00071 
Chen, Z. Q., Mou, R. T., Feng, D. X., Wang, Z., and Chen, G. (2017). The role of nitric oxide in stroke. Med. Gas Res. 7, 194-203. doi: 10.4103/2045-9912.215750

Cheng, N. T., and Kim, A. S. (2015). Intravenous thrombolysis for acute ischemic stroke within 3 hours versus between 3 and 4.5 hours of symptom onset. Neurohospitalist 5, 101-109. doi: 10.1177/1941874415583116

Cho, H., Zhao, X., Hatori, M., Yu, R. T., Barish, G. D., Lam, M. T., et al. (2012). Regulation of circadian behaviour and metabolism by REV-ERB- $\alpha$ and REV-ERB- $\beta$. Nature 485, 123-127. doi: 10.1038/nature11048

Choy, M., and Salbu, R. L. (2011). Jet lag:current and potential therapies. P T 36, 221-231. doi: 10.17238/issn2223-2524.2016.3.13

Coca, A. (1994). Circadian rhythm and blood pressure control: physiological and pathophysiological factors. J. Hypertens. 12, S13-S21.

Comas, M., Gordon, C. J., Oliver, B. G., Stow, N. W., King, G., Sharma, P., et al. (2017). A circadian based inflammatory response - implications for respiratory disease and treatment. Sleep Sci. Pract. 1, 1-19. doi: 10.1186/s41606-0170019-2

Conroy, D. A., Spielman, A. J., and Scott, R. Q. (2005). Daily rhythm of cerebral blood flow velocity. J. Circadia. Rhythms 3, 1-11. doi: 10.1186/1740-3391-3-3

Costa, G., Åkerstedt, T., Nachreiner, F., Baltieri, F., Carvalhais, J., Folkard, S., et al. (2004). Flexible working hours, health, and well-being in europe: some considerations from a SALTSA project. Chronobiol. Int. 21, 831-844. doi: 10. 1081/CBI-200035935

Crowley, S. J., Acebo, C., and Carskadon, M. A. (2007). Sleep, circadian rhythms, and delayed phase in adolescence. Sleep Med. 8, 602-612. doi: 10.1016/j.sleep. 2006.12.002

Cuddapah, V. A., Zhang, S. L., and Sehgal, A. (2019). Regulation of the bloodbrain barrier by circadian rhythms and sleep. Trends Neurosci. 42, 500-510. doi: 10.1016/j.tins.2019.05.001

Curtis, A. M., Cheng, Y., Kapoor, S., Reilly, D., Price, T. S., and FitzGerald, G. A. (2007). Circadian variation of blood pressure and the vascular response to asynchronous stress. Proc. Natl. Acad. Sci. U.S.A. 104, 3450-3455. doi: 10.1073/ pnas.0611680104

Daan, S., and Aschoff, J. (1982). "Circadian contributions to survival," in Vertebrate Circadian Systems. Proceedings in Life Sciences, eds J. Aschoff, S. Daan, and G. A. Groos (Berlin: Springer), 305-321. doi: 10.1007/978-3-642-68651-1_34

Davidson, A. J., Besing, R. C., Menaker, M., Gewirtz Ehlen, A. T., Paul, K., Gamble, K. L., et al. (2010). Dysregulation of inflammatory responses by chronic circadian disruption. J. Immunol. 185, 5796-5805. doi: 10.4049/jimmunol. 1001026

DeBruyne, J. P., Weaver, D. R., and Reppert, S. M. (2007). CLOCK and NPAS2 have overlapping roles in the suprachiasmatic circadian clock. Nat. Neurosci. 10, 543-545. doi: 10.1038/nn1884

Denniff, M., Turrell, H. E., Vanezis, A., and Rodrigo, G. C. (2014). The time-ofday variation in vascular smooth muscle contractility depends on a nitric oxide signalling pathway. J. Mol. Cell. Cardiol. 66, 133-140. doi: 10.1016/j.yjmcc.2013. 11.009

Denny, M. C., Boehme, A. K., Dorsey, A. M., George, A. J., Yeh, A. D., Albright, K. C., et al. (2014). Wake-up strokes are similar to known-onset morning strokes in severity and outcome. J. Neurol. Neurol. Disord. 1:102. doi: 10.15744/ 2454-4981.1.102

Do, M. T. H., and Yau, K. W. (2010). Intrinsically photosensitive retinal ganglion cells. Physiol. Rev. 90, 1547-1581. doi: 10.1152/physrev.00013.2010

Durgan, D. J., Crossland, R. F., and Bryan, R. M. (2017). The rat cerebral vasculature exhibits time-of-day-dependent oscillations in circadian clock genes and vascular function that are attenuated following obstructive sleep apnea. J. Cereb. Blood Flow Metab. 37, 2806-2819. doi: 10.1177/ 0271678X16675879

Durgan, D. J., Pulinilkunnil, T., Villegas-Montoya, C., Garvey, M. E., Frangogiannis, N. G., Michael, L. H., et al. (2010). Short communication ischemia/reperfusion tolerance is time-of-day-dependent mediation by the cardiomyocyte circadian clock from the division of cardiovascular diseases. J. Immunol. 185, 5796-5805. doi: 10.1161/CIRCRESAHA.109.209346

Durgan, D. J., Tsai, J. Y., Grenett, M. H., Pat, B. M., Ratcliffe, W. F., VillegasMontoya, C., et al. (2011). Evidence suggesting that the cardiomyocyte circadian clock modulates responsiveness of the heart to hypertrophic stimuli in mice. Chronobiol. Intern. 28, 187-203. doi: 10.3109/07420528.2010.550406

Earnest, D. J., Neuendorff, N., Coffman, J., Selvamani, A., and Sohrabji, F. (2016). Sex differences in the impact of shift work schedules on pathological outcomes in an animal model of ischemic stroke. Endocrinology 157, 2836-2843. doi: 10.1210/en.2016-1130

Ella, K., Csépányi-Kömi, R., and Káldi, K. (2016). Circadian regulation of human peripheral neutrophils. Brain Behav. Immun. 57, 209-221. doi: 10.1016/j.bbi. 2016.04.016

Elliott, W. J. (1998). Circadian variation in the timing of stroke onset: A metaanalysis. Stroke 29, 992-996. doi: 10.1161/01.STR.29.5.992

Falchi, F., Cinzano, P., Duriscoe, D., Kyba, C. C. M., Elvidge, C. D., Baugh, K., et al. (2016). The new world atlas of artificial night sky brightness. Sci. Adv. 2:e1600377. doi: 10.1126/sciadv.1600377

Falchi, F., Cinzano, P., Elvidge, C. D., Keith, D. M., and Haim, A. (2011). Limiting the impact of light pollution on human health, environment and stellar visibility. J. Environ. Manag. 92, 2714-2722. doi: 10.1016/j.jenvman.2011. 06.029

Fonarow, G. C., Smith, E. E., Saver, J. L., Reeves, M. J., Hernandez, A. F., Peterson, E. D., et al. (2011). Improving door-to-needle times in acute ischemic stroke: the design and rationale for the American heart association/American stroke association's target: stroke initiative. Stroke 42, 2983-2989. doi: 10.1161/ STROKEAHA.111.621342

Fonken, L. K., Aubrecht, T. G., Meléndez-Fernández, O. H., Weil, Z. M., and Nelson, R. J. (2013). Dim light at night disrupts molecular circadian rhythms and increases body weight. J. Biol. Rhythms 28, 262-271. doi: 10.1177/ 0748730413493862

Fonken, L. K., Frank, M. G., Kitt, M. M., Barrientos, R. M., Watkins, L. R., and Maier, S. F. (2015). Microglia inflammatory responses are controlled by an intrinsic circadian clock. Brain Behav. Immun. 45, 171-179. doi: 10.1016/j.bbi. 2014.11.009

Fu, Y., Zhong, H., Wang, M. H. H., Luo, D. G., Liao, H. W., Maeda, H., et al. (2005). Intrinsically photosensitive retinal ganglion cells detect light with a vitamin A-based photopigment, melanopsin. Proc. Natl. Acad. Sci. U.S.A. 102, 10339-10344. doi: 10.1073/pnas.0501866102

Gamlin, P. D. R., McDougal, D. H., Pokorny, J., Smith, V. C., Yau, K. W., and Dacey, D. M. (2007). Human and macaque pupil responses driven by melanopsincontaining retinal ganglion cells. Vis. Res. 47, 946-954. doi: 10.1016/j.visres. 2006.12.015

Gaston, K. J., Davies, T. W., Bennie, J., and Hopkins, J. (2012). REVIEW: reducing the ecological consequences of night-time light pollution: options and developments. J. Appl. Ecol. 49, 1256-1266. doi: 10.1111/j.1365-2664.2012. 02212.x

Gaston, K. J., Duffy, J. P., Gaston, S., Bennie, J., and Davies, T. W. (2014). Human alteration of natural light cycles: causes and ecological consequences. Oecologia 176, 917-931. doi: 10.1007/s00442-014-3088-2

Gibbs, J., Ince, L., Matthews, L., Mei, J., Bell, T., Yang, N., et al. (2014). An epithelial circadian clock controls pulmonary inflammation and glucocorticoid action. Nat. Med. 20, 919-926. doi: 10.1038/nm.3599

Golombek, D. A., and Rosenstein, R. E. (2010). Physiology of circadian entrainment. Physiol. Rev. 90, 1063-1102. doi: 10.1152/physrev.00009.2009

Griffin, P., Dimitry, J. M., Sheehan, P. W., Lananna, B. V., Guo, C., Robinette, M. L., et al. (2019). Circadian clock protein Rev-erb $\alpha$ regulates neuroinflammation. Proc. Natl. Acad. Sci. U.S.A. 116, 5102-5107. doi: 10.1073/pnas.1812405116

Guillaumond, F., Dardente, H., Giguère, V., and Cermakian, N. (2005). Differential control of Bmall circadian transcription by REV-ERB and ROR nuclear receptors. J. Biol. Rhythms 20, 391-403. doi: 10.1177/0748730405277232

Haus, E., Cusulos, M., Sackett-Lundeen, L., and Swoyer, J. (1990). Circadian variations in blood coagulation parameters, alpha-antitrypsin antigen and platelet aggregation and retention in clinically healthy subjects. Chronobiol. Intern. 7, 203-216. doi: 10.3109/07420529009056976

Hemmeryckx, B., Frederix, L., and Lijnen, H. R. (2019). Deficiency of Bmall disrupts the diurnal rhythm of haemostasis. Exper. Gerontol. 118, 1-8. doi: 10.1016/j.exger.2018.12.017

Hemmeryckx, B., van Hove, C. E., Fransen, P., Emmerechts, J., Kauskot, A., Bult, H., et al. (2011). Progression of the prothrombotic state in aging bmalldeficient mice. Arterioscleros. Thromb. Vasc. Biol. 31, 2552-2559. doi: 10.1161/ ATVBAHA.111.229062

Herculano-Houzel, S. (2014). The glia/neuron ratio: how it varies uniformly across brain structures and species and what that means for brain physiology and evolution. Glia 62, 1377-1391. doi: 10.1002/glia. 22683 
Hodkinson, D. J., Zunszain, P. A., Pariante, C. M., Lazurenko, V., Zelaya, F. O., Howard, M. A., et al. (2014). Circadian and homeostatic modulation of functional connectivity and regional cerebral blood flow in humans under normal entrained conditions. J. Cereb. Blood Flow Metab. 34, 1493-1499. doi: $10.1038 / j \mathrm{jbfm} .2014 .109$

Huang, J., Upadhyay, U. M., and Tamargo, R. J. (2006). Inflammation in stroke and focal cerebral ischemia. Surg. Neurol. 66, 232-245. doi: 10.1016/j.surneu.2005. 12.028

Huang, P. L. (2007). "eNOS and nNOS in stroke," in Handbook of Neurochemistry and Molecular Neurobiology: Acute Ischemic Injury and Repair in the Nervous System, eds A. Lajtha, and P. H. Chan (Cham: Springer), 47-63. doi: 10.1007/ 978-0-387-30383-3_4

Huang, Z., Huang, P. L., Ma, J., Meng, W., Ayata, C., Fishman, M. C., et al. (1996). Enlarged infarcts in endothelial nitric oxide synthase knockout mice are attenuated by nitro-L-arginine. J. Cereb. Blood Flow Metab. 16, 981-987. doi: 10.1097/00004647-199609000-00023

Hurley, J. M., Loros, J. J., and Dunlap, J. C. (2016). Circadian oscillators: around the transcription-translation feedback loop and on to output hhs public access. Trends Biochem. Sci. 41, 834-846. doi: 10.1016/j.tibs.2016.07.009

Iadecola, C., and Anrather, J. (2011). The immunology of stroke: from mechanisms to translation. Nat. Med. 17, 796-808. doi: 10.1038/nm.2399

Jian, Z., Liu, R., Zhu, X., Smerin, D., Zhong, Y., Gu, L., et al. (2019). The involvement and therapy target of immune cells after ischemic stroke. Front. Immunol. 10:2167. doi: 10.3389/fimmu.2019.02167

Jickling, G. C., Liu, D., Stamova, B., Ander, B. P., Zhan, X., Lu, A., et al. (2014). Hemorrhagic transformation after ischemic stroke in animals and humans. J. Cereb. Blood Flow Metab. 34, 185-199. doi: 10.1038/jcbfm.2013.203

Jickling, G. C., Liu, D. Z., Ander, B. P., Stamova, B., Zhan, X., and Sharp, F. R. (2015). Targeting neutrophils in ischemic stroke: translational insights from experimental studies. J. Cereb. Blood Flow Metab. 35, 888-901. doi: 10.1038/ jcbfm.2015.45

Kamel, H., and Iadecola, C. (2012). Brain-immune interactions and ischemic stroke: clinical implications. Archiv. Neurol. 69, 576-581. doi: 10.1001/ archneurol.2011.3590

Kastrup, A., Gröschel, K., Ringer, T. M., Redecker, C., Cordesmeyer, R., Witte, O. W., et al. (2008). Early disruption of the bloodbrain barrier after thrombolytic therapy predicts hemorrhage in patients with acute stroke. Stroke 39, 2385-2387. doi: 10.1161/STROKEAHA.107.505420

Keaney, J., and Campbell, M. (2015). The dynamic blood-brain barrier. FEBS J. 282, 4067-4079. doi: 10.1111/febs.13412

Kim, M., de la Peña, J. B., Cheong, J. H., and Kim, H. J. (2018). Neurobiological functions of the period circadian clock 2 gene, per2. Biomol. Ther. 26, 358-367. doi: 10.4062/biomolther.2017.131

Klein, D. C., and Weller, J. L. (1972). Rapid light-induced decrease in pineal serotonin $\mathrm{N}$-acetyltransferase activity. Science 177, 532-533. doi: 10.1126/ science.177.4048.532

Korompeli, A., Muurlink, O., Kavrochorianou, N., Katsoulas, T., Fildissis, G., and Baltopoulos, G. (2017). Circadian disruption of ICU patients: a review of pathways, expression, and interventions. J. Critic. Care 38, 269-277. doi: 10.1016/j.jcrc.2016.12.006

Kostenko, E., and Petrova, L. (2018). "Features of circadian rhythms in patients with cerebrovascular diseases," in Circadian Rhythm - Cellular and Molecular Mechanisms, ed. M. A. El-Esawi (London: InTech), doi: 10.5772/intechopen. 75963

Kurnik, P. B. (1995). Circadian variation in the efficacy of tissue-type plasminogen activator. Circulation 91, 1341-1346. doi: 10.1161/01.CIR.91.5.1341

Kyba, C. C. M., Kuester, T., de Miguel, A. S., Baugh, K., Jechow, A., Hölker, F., et al. (2017a). Artificially lit surface of Earth at night increasing in radiance and extent. Sci. Adv. 3:e1701528. doi: 10.1126/sciadv.1701528

Kyba, C. C. M., Mohar, A., and Posch, T. (2017b). How bright is moonlight? Astron. Geophys. 58, 31-31. doi: 10.1093/astrogeo/atx025

Labrecque, N., and Cermakian, N. (2015). Circadian clocks in the immune system. J. Biol. Rhythms 30, 277-290. doi: 10.1177/0748730415577723

Lago, A., Geffner, D., Tembl, J., Landete, L., Valero, C., and Baquero, M. (1998). Circadian variation in acute ischemic stroke: a hospital-based study. Stroke 29, 1873-1875. doi: 10.1161/01.STR.29.9.1873
Lakhan, S. E., Kirchgessner, A., Tepper, D., and Leonard, A. (2013). Matrix metalloproteinases and blood-brain barrier disruption in acute ischemic stroke. Front. Neurol. 4:32. doi: 10.3389/fneur.2013.00032

Lam, M. T. Y., Cho, H., Lesch, H. P., Gosselin, D., Heinz, S., Tanaka-Oishi, Y., et al. (2013). Rev-Erbs repress macrophage gene expression by inhibiting enhancerdirected transcription. Nature 498, 511-515. doi: 10.1038/nature12209

Lananna, B. V., Nadarajah, C. J., Izumo, M., Cedeño, M. R., Xiong, D. D., Dimitry, J., et al. (2018). Cell-autonomous regulation of astrocyte activation by the circadian clock protein BMAL1. Cell Rep. 25, 1-9.e5. doi: 10.1016/j.celrep.2018. 09.015

Lawson, L. J., Perry, V. H., and Gordon, S. (1992). Turnover of resident microglia in the normal adult mouse brain. Neuroscience 48, 405-415. doi: 10.1016/03064522(92)90500-2

Lee, Y. J., Han, D. H., Pak, Y. K., and Cho, S. (2012). Circadian regulation of low density lipoprotein receptor promoter activity by CLOCK/BMAL1, Hes1 and Hes6. Exper. Mol. Med. 44, 642-652. doi: 10.3858/emm.2012.44.11.073

Lembach, A., Stahr, A., Ali, A. A. H., Ingenwerth, M., and von Gall, C. (2018). Sexdependent effects of bmall-deficiency on mouse cerebral cortex infarction in response to photothrombotic stroke. Intern. J. Mol. Sci. 19:3124. doi: 10.3390/ ijms19103124

Lewis, P., Korf, H. W., Kuffer, L., Groß, J. V., and Erren, T. C. (2018). Exercise time cues (zeitgebers) for human circadian systems can foster health and improve performance: a systematic review. BMJ Open Sport Exerc. Med. 4:443. doi: 10.1136/bmjsem-2018-000443

Liu, S., Premont, R. T., and Rockey, D. C. (2014). Endothelial nitric-oxide synthase (eNOS) is activated through G-protein-coupled receptor kinase-interacting protein 1 (GIT1) tyrosine phosphorylation and Src protein. J. Biol. Chem. 289, 18163-18174. doi: 10.1074/jbc.M113.521203

Lo, E. H., Broderick, J. P., and Moskowitz, M. A. (2004). tPA and proteolysis in the neurovascular unit. Stroke 35, 354-356. doi: 10.1161/01.STR.0000115164. $80010.8 \mathrm{~A}$

Loane, D. J., and Byrnes, K. R. (2010). Role of microglia in neurotrauma. Neurotherapeutics 7, 366-377. doi: 10.1016/j.nurt.2010.07.002

Lowrey, P. L., Shimomura, K., Antoch, M. P., Yamazaki, S., Zemenides, P. D., Ralph, M. R., et al. (2000). Positional syntenic cloning and functional characterization of the mammalian circadian mutation tau. Science 288, 483491. doi: $10.1126 /$ science. 288.5465 .483

Lowrey, P. L., and Takahashi, J. S. (2000). Genetics of the mammalian circadian system: photic entrainment, circadian pacemaker mechanisms, and posttranslational regulation. Annu. Rev. Genet. 34, 533-562. doi: 10.1146/ annurev.genet.34.1.533

Marcheva, B., Ramsey, K. M., Peek, C. B., Affinati, A., Maury, E., and Bass, J. (2013). Circadian clocks and metabolism. Handb. Exper. Pharmacol. 217, 127-155. doi: 10.1007/978-3-642-25950-0_6

Marie-Pierre Hardy, C., Labrecque, N., Erin Fortier, N. E., Rooney, J., and Dardente, H. (2021). Circadian variation of the response of T cells to antigen. J. Immunol. 187, 6291-6300. doi: 10.4049/jimmunol.1004030

Marler, J. R., Price, T. R., Clark, G. L., Muller, J. E., Robertson, T., Mohr, J. P., et al. (1989). Morning increase in onset of ischemic stroke. Stroke 20, 473-476. doi: $10.1161 / 01 . S T R .20 .4 .473$

Massin, M. M., Maeyns, K., Withofs, N., Ravet, F., Gerard, P., and Healy, M. J. R. (2000). Circadian rhythm of heart rate and heart rate variability. Archiv. Dis. Childhood 83, 179-182. doi: 10.1136/adc.83.2.179

Mendoza-Viveros, L., Bouchard-Cannon, P., Hegazi, S., Cheng, A. H., Pastore, S., and Cheng, H. Y. M. (2017). Molecular modulators of the circadian clock: lessons from flies and mice. Cell. Mol. Life Sci. 74, 1035-1059. doi: 10.1007/ s00018-016-2378-8

Millar-Craig, M. W., Bishop, C. N., and Raftery, E. B. (1978). Circadian variation of blood-pressure. Lancet 311, 795-797. doi: 10.1016/S0140-6736(78)92998-7

Miller, D. J., Simpson, J. R., Silver, B., and Silver, B. (2011). Safety of thrombolysis in acute ischemic stroke: a review of complications, risk factors, and newer technologies. Neurohospitalist 1, 138-147. doi: 10.1177/1941875211408731

Molcan, L., Sutovska, H., Okuliarova, M., Senko, T., Krskova, L., and Zeman, M. (2019). Dim light at night attenuates circadian rhythms in the cardiovascular system and suppresses melatonin in rats. Life Sci. 231:116568. doi: 10.1016/j.lfs. 2019.116568 
Morrell, C. N., Sun, H., Swaim, A. M., and Baldwin, W. M. (2007). Platelets an inflammatory force in transplantation. Am. J. Transplant. 7, 2447-2454. doi: 10.1111/j.1600-6143.2007.01958.x

Morris, C. J., Yang, J. N., and Scheer, F. A. J. L. (2012). The impact of the circadian timing system on cardiovascular and metabolic function. Prog. Brain Res. 199, 337-358. doi: 10.1016/B978-0-444-59427-3.00019-8

Mozaffarian, D., Benjamin, E. J., Go, A. S., Arnett, D. K., Blaha, M. J., Cushman, M., et al. (2016). Heart disease and stroke statistics-2016 update a report from the American Heart association. Circulation 133, e38-e48. doi: 10.1161/CIR. 0000000000000350

Nakazato, R., Kawabe, K., Yamada, D., Ikeno, S., Mieda, M., Shimba, S., et al. (2017). Disruption of Bmal1 impairs blood-brain barrier integrity via pericyte dysfunction. J. Neurosci. 37, 10052-10062. doi: 10.1523/JNEUROSCI.3639-16. 2017

Navara, K. J., and Nelson, R. J. (2007). The dark side of light at night: physiological, epidemiological, and ecological consequences. J. Pineal Res. 43, 215-224. doi: 10.1111/j.1600-079X.2007.00473.x

Nelson, R. J., and DeVries, A. C. (2017). Medical hypothesis: light at night is a factor worth considering in critical care units. Adv. Integrat. Med. 4, 115-120. doi: 10.1016/j.aimed.2017.12.001

Nguyen, K. D., Fentress, S. J., Qiu, Y., Yun, K., Cox, J. S., and Chawla, A. (2013). Circadian gene Bmal1 regulates diurnal oscillations of Ly6Chi inflammatory monocytes. Science 341, 1483-1488. doi: 10.1126/science.1240636

Obayashi, K., Saeki, K., and Kurumatani, N. (2018). Bedroom Light Exposure at Night and the Incidence of Depressive Symptoms: A Longitudinal Study of the HEIJO-KYO Cohort. Am. J. Epidemiol. 187, 427-434. doi: 10.1093/aje/ kwx290

Ohkura, N., Oishi, K., Fukushima, N., Kasamatsu, M., Atsumi, G. I., Ishida, N., et al. (2006). Circadian clock molecules CLOCK and CRYs modulate fibrinolytic activity by regulating the PAI-1 gene expression. J. Thromb. Haemost. 4, 24782485. doi: 10.1111/j.1538-7836.2006.02210.x

Oishi, K. (2009). Plasminogen activator inhibitor-1 and the circadian clock in metabolic disorders. Clin. Exper. Hypertens. 31, 208-219. doi: 10.1080/ 10641960902822468

Okamoto-Uchida, Y., Izawa, J., Nishimura, A., Hattori, A., Suzuki, N., and Hirayama, J. (2019). Post-translational modifications are required for circadian clock regulation in vertebrates. Curr. Genom. 20, 332-339. doi: 10.2174/ 1389202919666191014094349

Palta, S., Saroa, R., and Palta, A. (2014). Overview of the coagulation system. Indian J. Anaesthesia 58, 515-523. doi: 10.4103/0019-5049.144643

Panza, J. A., Epstein, S. E., and Quyyumi, A. A. (1991). Circadian variation in vascular tone and its relation to $\alpha$-sympathetic vasoconstrictor activity. New Engl. J. Med. 325, 986-990. doi: 10.1056/NEJM199110033251402

Paschos, G. K., and FitzGerald, G. A. (2010). Circadian clocks and vascular function. Circ. Res. 106, 833-841. doi: 10.1161/CIRCRESAHA.109.211706

Patke, A., Young, M. W., and Axelrod, S. (2020). Molecular mechanisms and physiological importance of circadian rhythms. Nat. Rev. Mol. Cell Biol. 21, 67-84. doi: 10.1038/s41580-019-0179-2

Peek, C. B., Levine, D. C., Cedernaes, J., Taguchi, A., Kobayashi, Y., Tsai, S. J., et al. (2017). Circadian clock interaction with HIF1 $\alpha$ mediates oxygenic metabolism and anaerobic glycolysis in skeletal muscle. Cell Metab. 25, 86-92. doi: 10.1016/ j.cmet.2016.09.010

Pinheiro, M. A. L., Kooij, G., Mizee, M. R., Kamermans, A., Enzmann, G., Lyck, R., et al. (2016). Immune cell trafficking across the barriers of the central nervous system in multiple sclerosis and stroke. Biochim. Biophys. Acta Mol. Basis Dis. 1862, 461-471. doi: 10.1016/j.bbadis.2015.10.018

Preitner, N., Damiola, F., Molina, L.-L., Zakany, J., Duboule, D., Albrecht, U., et al. (2002). The orphan nuclear receptor REV-ERB $\alpha$ controls circadian transcription within the positive limb of the mammalian circadian oscillator. Cell 110, 251-260. doi: 10.1016/S0092-8674(02)00825-5

Ramsey, A. M., Stowie, A., Castanon-Cervantes, O., and Davidson, A. J. (2020). Environmental circadian disruption increases stroke severity and dysregulates immune response. J. Biol. Rhythms 35, 368-376. doi: 10.1177/ 0748730420929450

Richards, J., Cheng, K. Y., All, S., Skopis, G., Jeffers, L., Lynch, I. J., et al. (2013). A role for the circadian clock protein Perl in the regulation of aldosterone levels and renal Na+ retention. Am. J. Physiol. Renal Physiol. 305, F1697-F1704. doi: 10.1152/ajprenal.00472.2013
Rodrigo, G. C., and Denniff, M. (2016). Time-of-day variation in vascular function. Exper. Physiol. 101, 1030-1034. doi: 10.1113/EP085780

Rollag, M. D., Panke, E. S., Trakulrungsi, W., Trakulrungsi, C., and Reiter, R. J. (1980). Quantification of daily melatonin synthesis in the hamster pineal gland. Endocrinology 106, 231-236. doi: 10.1210/endo-106-1-231

Rosenberg, G. A. (2002). Matrix metalloproteinases in neuroinflammation. Glia 39, 279-291. doi: 10.1002/glia.10108

Rumanova, V. S., Okuliarova, M., and Zeman, M. (2020). Differential effects of constant light and dim light at night on the circadian control of metabolism and behavior. Intern. J. Mol. Sci. 21, 1-20. doi: 10.3390/ijms21155478

Salavaty, A. (2015). Carcinogenic effects of circadian disruption: an epigenetic viewpoint. Chin. J. Cancer 34:38. doi: 10.1186/s40880-015-0043-5

Sato, T. K., Panda, S., Miraglia, L. J., Reyes, T. M., Rudic, R. D., McNamara, P., et al. (2004). A functional genomics strategy reveals rora as a component of the mammalian circadian clock. Neuron 43, 527-537. doi: 10.1016/j.neuron.2004. 07.018

Savvidis, C., and Koutsilieris, M. (2012). Circadian rhythm disruption in cancer biology. Mol. Med. 18, 1249-1260. doi: 10.2119/molmed.2012.00077

Scheiermann, C., Kunisaki, Y., and Frenette, P. S. (2013). Circadian control of the immune system. Nat. Rev. Immunol. 13, 190-198. doi: 10.1038/nri3386

Scheer, F. A. J. L., and Shea, S. A. (2014). Human circadian system causes a morning peak in prothrombotic plasminogen activator inhibitor-1 (PAI-1) independent of the sleep/wake cycle. Blood 123, 590-593. doi: 10.1182/blood2013-07-517060

Schoenhard, J. A., Smith, L. H., Painter, C. A., Eren, M., Johnson, C. H., and Vaughan, D. E. (2003). Regulation of the PAI-1 promoter by circadian clock components: differential activation by BMAL1 and BMAL2. J. Mol. Cell. Cardiol. 35, 473-481. doi: 10.1016/S0022-2828(03) 00051-8

Schroder, E. A., Lefta, M., Zhang, X., Bartos, D., Feng, H. Z., Zhao, Y., et al. (2013). The cardiomyocyte molecular clock, regulation of Scn5a, and arrhythmia susceptibility. Am. J. Physiol. Cell Physiol. 304, C954-C965. doi: 10.1152/ajpcell. 00383.2012

Schwartz, W. J., Tavakoli-Nezhad, M., Lambert, C. M., Weaver, D. R., and de La Iglesia, H. O. (2011). Distinct patterns of Period gene expression in the suprachiasmatic nucleus underlie circadian clock photoentrainment by advances or delays. Proc. Natl. Acad. Sci. U.S.A. 108, 17219-17224. doi: 10.1073/ pnas. 1107848108

Seet, R. C. S., Zhang, Y., Wijdicks, E. F. M., and Rabinstein, A. A. (2014). Thrombolysis outcomes among obese and overweight stroke patients: an age-and national institutes of health stroke scale-matched comparison background: whether obese and overweight stroke patients respond differently to. J. Stroke Cerebrovasc. Dis. 23, 1-6. doi: 10.1016/j.jstrokecerebrovasdis.2012. 04.001

Serin, Y., and Acar Tek, N. (2019). Effect of circadian rhythm on metabolic processes and the regulation of energy balance. Ann. Nutr. Metab. 74, 322-330. doi: 10.1159/000500071

Shearman, L. P., Zylka, M. J., Weaver, D. R., Kolakowski, L. F., and Reppert, S. M. (1997). Two period homologs: circadian expression and photic regulation in the suprachiasmatic nuclei. Neuron 19, 1261-1269. doi: 10.1016/S0896-6273(00) 80417- 1

Shi, K., Wood, K., Shi, F. D., Wang, X., and Liu, Q. (2018). Stroke-induced immunosuppression and poststroke infection. Stroke Vasc. Neurol. 3, 34-41. doi: 10.1136/svn-2017-000123

Shi, S. Q., Ansari, T. S., McGuinness, O. P., Wasserman, D. H., and Johnson, C. H. (2013). Circadian disruption leads to insulin resistance and obesity. Curr. Biol. 23, 372-381. doi: 10.1016/j.cub.2013.01.048

Shigeyoshi, Y., Taguchi, K., Yamamoto, S., Takekida, S., Yan, L., Tei, H., et al. (1997). Light-induced resetting of a mammalian circadian clock is associated with rapid induction of the mPer1 transcript. Cell 91, 1043-1053. doi: 10.1016/ S0092-8674(00)80494-8

Shivshankar, P., Fekry, B., Eckel-Mahan, K., and Wetsel, R. A. (2020). Circadian clock and complement immune system-complementary control of physiology and pathology? Front. Cell. Infect. Microbiol. 10:418. doi: 10.3389/fcimb.2020. 00418

Sims, N. R., and Anderson, M. F. (2002). Mitochondrial contributions to tissue damage in stroke. Neurochem. Intern. 40, 511-526. doi: 10.1016/S01970186(01)00122-X 
Sofroniew, M. V. (2015). Astrogliosis. Cold Spring Harb. Perspect. Biol. 7:a020420. doi: 10.1101/cshperspect.a020420

Somanath, P. R., Podrez, E. A., Chen, J., Ma, Y., Marchant, K., Antoch, M., et al. (2011). Deficiency in core circadian protein Bmall is associated with a prothrombotic and vascular phenotype. J. Cell. Physiol. 226, 132-140. doi: $10.1002 /$ jcp. 22314

Soulban, G., and Labrecque, G. (1989). Circadian rhythms of blood clotting time and coagulation factors II, VII, IX and X in rats. Life Sci. 45, 2485-2489. doi: 10.1016/0024-3205(89)90015-5

Stephan, F. K. (2002). The "Other" circadian system: food as a Zeitgeber. J. Biol. Rhythms 17, 284-292. doi: 10.1177/074873040201700402

Stow, L. R., Richards, J., Cheng, K. Y., Lynch, I. J., Jeffers, L. A., Greenlee, M. M., et al. (2012). The circadian protein period 1 contributes to blood pressure control and coordinately regulates renal sodium transport genes. Hypertension 59, 1151-1156. doi: 10.1161/HYPERTENSIONAHA.112.190892

Stubblefield, J. J., and Lechleiter, J. D. (2019). Time to target stroke: examining the circadian system in stroke. Yale J. Biol. Med. 92, 349-357.

Sumii, T., and Lo, E. H. (2002). Involvement of matrix metalloproteinase in thrombolysis-associated hemorrhagic transformation after embolic focal ischemia in rats. Stroke 33, 831-836. doi: 10.1161/hs0302.104542

Takano, T., Oberheim, N. A., Cotrina, M. L., and Nedergaard, M. (2009). Astrocytes and ischemic injury. Stroke 40(3 Suppl.), S8-S12. doi: 10.1161/STROKEAHA. 108.533166

Tang, L., and Han, X. (2013). The urokinase plasminogen activator system in breast cancer invasion and metastasis. Biomed. Pharmacother. 67, 179-182. doi: 10.1016/j.biopha.2012.10.003

Thapan, K., Arendt, J., and Skene, D. J. (2001). An action spectrum for melatonin suppression: evidence for a novel non-rod, non-cone photoreceptor system in humans. J. Physiol. 535, 261-267. doi: 10.1111/j.1469-7793.2001.t01-1-00261.x

Thosar, S. S., Butler, M. P., and Shea, S. A. (2018). Role of the circadian system in cardiovascular disease. J. Clin. Investig. 128, 2157-2167. doi: 10.1172/JCI80590

Tosini, G., and Menaker, M. (1996). Circadian rhythms in cultured mammalian retina. Science 272, 419-421. doi: 10.1126/science.272.5260.419

Travnickova-Bendova, Z., Cermakian, N., Reppert, S. M., and Sassone-Corsi, P. (2002). Bimodal regulation of mPeriod promoters by CREB-dependent signaling and CLOCK/BMAL1 activity. Proc. Natl. Acad. Sci. U.S.A. 99, 77287733. doi: 10.1073/pnas.102075599

Turin, T. C., Kita, Y., Rumana, N., Nakamura, Y., Takashima, N., Ichikawa, M., et al. (2012). Is there any circadian variation consequence on acute case fatality of stroke? Takashima Stroke Registry, Japan (1990-2003). Acta Neurol. Scand. 125, 206-212. doi: 10.1111/j.1600-0404.2011.01522.x

Valdez, P., Ramírez, C., and García, A. (1996). Delaying and extending sleep during weekends: sleep recovery or circadian effect? Chronobiol. Intern. 13, 191-198. doi: $10.3109 / 07420529609012652$

van der Horst, G. T. J., Muiitjens, M., Kobayashi, K., Takano, R., Kanno, S. I., Takao, M., et al. (1999). Mammalian Cry1 and Cry2 are essential for maintenance of circadian rhythms. Nature 398, 627-630. doi: 10.1038/19323

van Rossum, D., and Hanisch, U. K. (2004). Microglia. Metab. Brain Dis. 19, 393-411. doi: 10.1023/B:MEBR.0000043984.73063.d8

Wahl, S., Engelhardt, M., Schaupp, P., Lappe, C., and Ivanov, I. V. (2019). The inner clock-Blue light sets the human rhythm. J. Biophoton. 12:e201900102. doi: $10.1002 /$ jbio.201900102

Walker, W. H., Borniger, J. C., Gaudier-Diaz, M. M., Hecmarie MeléndezFernández, O., Pascoe, J. L., Courtney DeVries, A., et al. (2020). Acute exposure to low-level light at night is sufficient to induce neurological changes and depressive-like behavior. Mol. Psychiatry 25, 1080-1093. doi: 10.1038/s41380019-0430-4

Wang, S. J., and Chen, M. Y. (2020). The effects of sunlight exposure therapy on the improvement of depression and quality of life in post-stroke patients: a RCT study. Heliyon 6:e04379. doi: 10.1016/j.heliyon.2020.e04379

Wang, X., Lee, S. R., Arai, K., Lee, S. R., Tsuji, K., Rebeck, G. W., et al. (2003). Lipoprotein receptor-mediated induction of matrix metalloproteinase by tissue plasminogen activator. Nat. Med. 9, 1313-1317. doi: 10.1038/nm926

Wang, X.-L., Wolff, S. E. C., Korpel, N., Milanova, I., Sandu, C., Rensen, P. C. N., et al. (2020). Deficiency of the circadian clock gene bmall reduces microglial immunometabolism. Front. Immunol. 11:586399. doi: 10.3389/fimmu.2020. 586399
Weil, Z. M., Fonken, L. K., Walker, W. H., Bumgarner, J. R., Liu, J. A., MelendezFernandez, O. H., et al. (2020). Dim light at night exacerbates stroke outcome. Eur. J. Neurosci. 52, 4139-4146. doi: 10.1111/ejn.14915

Weil, Z. M., Karelina, K., Su, A. J., Barker, J. M., Norman, G. J., Zhang, N., et al. (2009). Time-of-day determines neuronal damage and mortality after cardiac arrest. Neurobiol. Dis. 36, 352-360. doi: 10.1016/j.nbd.2009.07.032

West, A., Jennum, P., Simonsen, S. A., Sander, B., Pavlova, M., and Iversen, H. K. (2017). Impact of naturalistic lighting on hospitalized stroke patients in a rehabilitation unit: design and measurement. Chronobiol. Intern. 34, 687-697. doi: 10.1080/07420528.2017.1314300

West, A., Simonsen, S. A., Zielinski, A., Cyril, N., Schønsted, M., Jennum, P., et al. (2019). An exploratory investigation of the effect of naturalistic light on depression, anxiety, and cognitive outcomes in stroke patients during admission for rehabilitation: a randomized controlled trial. Neuro Rehabil. 44, 341-351. doi: 10.3233/NRE-182565

Westgate, E. J., Cheng, Y., Reilly, D. F., Price, T. S., Walisser, J. A., Bradfield, C. A., et al. (2008). Genetic components of the circadian clock regulate thrombogenesis in vivo. Circulation 117, 2087-2095. doi: 10.1161/ CIRCULATIONAHA.107.739227

Wiebking, N., Maronde, E., and Rami, A. (2013). Increased neuronal injury in clock gene Per-1 deficient-mice after cerebral ischemia. Curr. Neurovasc. Res. 10, 112-125. doi: 10.2174/1567202611310020004

Wittmann, M., Dinich, J., Merrow, M., and Roenneberg, T. (2006). Social jetlag: misalignment of biological and social time. Chronobiol. Intern. 23, 497-509. doi: 10.1080/07420520500545979

Wright, K. P., Mchill, A. W., Birks, B. R., Griffin, B. R., Rusterholz, T., and Chinoy, E. D. (2013). Entrainment of the human circadian clock to the natural light-dark cycle. Curr. Biol. 23, 1554-1558. doi: 10.1016/j.cub.2013. 06.039

Xie, Z., Su, W., Liu, S., Zhao, G., Esser, K., Schroder, E. A., et al. (2015). Smoothmuscle BMAL1 participates in blood pressure circadian rhythm regulation. J. Clin. Invest. 125, 324-336. doi: 10.1172/JCI76881

Xu, S., Lu, J., Shao, A., Zhang, J. H., and Zhang, J. (2020). Glial cells: role of the immune response in ischemic stroke. Front. Immunol. 11:294. doi: 10.3389/ fimmu.2020.00294

Yamazaki, S., Numano, R., Abe, M., Hida, A., Takahashi, R. I., Ueda, M., et al. (2000). Resetting central and peripheral circadian oscillators in transgenic rats. Science 288, 682-685. doi: 10.1126/science.288.5466.682

Yan, L., and Silver, R. (2004). Resetting the brain clock: time course and localization of mPER1 and mPER2 protein expression in suprachiasmatic nuclei during phase shifts. Eur. J. Neurosci. 19, 1105-1109. doi: 10.1111/j.1460-9568.2004. 03189.x

Yang, X., Chu, H., Tang, Y., and Dong, Q. (2016). The role of connexin 43 in hemorrhagic transformation after thrombolysis in vivo and in vitro. Neuroscience 329, 54-65. doi: 10.1016/j.neuroscience.2016.04.040

Yang, Y., and Rosenberg, G. A. (2015). Matrix metalloproteinases as therapeutic targets for stroke. Brain Res. 1623, 30-38. doi: 10.1016/j.brainres.2015. 04.024

Yenari, M. A., Kauppinen, T. M., and Swanson, R. A. (2010). Microglial activation in stroke: therapeutic targets. Neurotherapeutics 7, 378-391. doi: 10.1016/j.nurt. 2010.07.005

Zhang, S. L., Yue, Z., Arnold, D. M., and Artiushin, G. (2018). A circadian clock in the blood-brain barrier regulates Xenobiotic Efflux. Cell 173, 130-139. doi: 10.1016/j.cell.2018.02.017

Zuchero, J. B., and Barres, B. A. (2015). Glia in mammalian development and disease. Development 142, 3805-3809. doi: 10.1242/dev.129304

Conflict of Interest: The authors declare that the research was conducted in the absence of any commercial or financial relationships that could be construed as a potential conflict of interest.

Copyright $\odot 2021$ Liu, Walton, DeVries and Nelson. This is an open-access article distributed under the terms of the Creative Commons Attribution License (CC BY). The use, distribution or reproduction in other forums is permitted, provided the original author(s) and the copyright owner(s) are credited and that the original publication in this journal is cited, in accordance with accepted academic practice. No use, distribution or reproduction is permitted which does not comply with these terms. 